J Health Econ. 2018 July ; 60: 1-15. doi:10.1016/j.jhealeco.2018.04.002.

\title{
Exploding asthma and ADHD caseloads: The role of medicaid managed care
}

\author{
Anna Chorniy ${ }^{\mathrm{a}}$, Janet Currie $^{\mathrm{b}}$, and Lyudmyla Sonchak ${ }^{\mathrm{C}}$ \\ aCenter for Health and Wellbeing, Princeton University, 173 Julis Romo Rabinowitz Building, \\ Princeton, NJ 08544, United States \\ bepartment of Economics, 185A Julis Romo Rabinowitz Building, Princeton, NJ 08544, United \\ States \\ 'Department of Economics, SUNY Oswego, 425 Mahar Hall, Oswego, NY 13126, United States
}

\section{Abstract}

In the U.S., nearly $11 \%$ of school-age children have been diagnosed with ADHD, and approximately $10 \%$ of children suffer from asthma. In the last decade, the number of children diagnosed with these conditions has inexplicably been on the rise. This increase has been concentrated in the Medicaid caseload nationwide. One of the most striking changes in Medicaid has been the transition from fee-for-service (FFS) reimbursement to Medicaid managed care (MMC), which had taken place in $80 \%$ of states by 2016. Using Medicaid claims from South Carolina, we show that this change contributed to the increase in asthma and ADHD caseloads. Empirically, we rely on variation in MMC enrollment due to a change in the "default" Medicaid plan from FFS to MMC, and on rich panel data that allow us to follow the same children before and after they were required to switch. We find that the transition from FFS to MMC explains about a third of the rise in the number of Medicaid children being treated for ADHD and asthma, along with increases in treatment for many other conditions. These are likely to be due to the incentives created by the risk adjustment and quality control systems in MMC.

\section{Keywords}

Medicaid; Managed care; Fee-for-service; Children's chronic conditions; ADHD; Asthma

\section{Introduction}

The prevalence of childhood chronic conditions has continued to increase over the past decade. This paper focuses on two of the most common childhood conditions: Asthma and attention-deficit hyperactivity disorder (ADHD). The number of children whose parents reported that they had ever been diagnosed with ADHD increased by two million between the 2003 and 2011 waves of the National Survey of Children's Health, rising to $11 \%$ of all school-aged children (Visser et al., 2014). Between 2001 and 2010, the number of children who had been diagnosed with asthma increased from 8.7 to $9.3 \%$, although the number who 
reported an asthma attack in the past month held steady and the number of asthma-related hospitalizations and deaths continued to fall (CDC, 2012). These asthma trends may reflect either more diagnoses of milder cases or better treatment for those who have been diagnosed.

In this paper, we propose and test the hypothesis that some of the increase in diagnoses for these childhood conditions was driven by changes in Medicaid, the means-tested public health insurance program that covers low to moderate income children. One motivation for this hypothesis is the observation that in national data, the increase in treatment for ADHD and asthma over the course of the 2000s was largely driven by children on Medicaid, and not by children with private health insurance coverage.

Figs. 1 and 2 are based on data from the national Medical Expenditure Panel Survey (MEPS), for children less than 17 years of age. Fig. 1 shows that while the overall number of children taking any kind of prescription drug fell, the fraction with prescriptions for ADHD medications rose, and all of the increase is accounted for by children on Medicaid. Fig. 2 shows that the fraction of children taking prescription drugs for asthma has also increased. Up to 2009, it increased at a similar rate for the privately and publicly insured, while after 2009, all of the increase has been among Medicaid recipients. ${ }^{1}$

One of the largest changes in Medicaid over the course of the 2000s is that it was converted from a largely "fee-for-service" (FFS) program, in which physicians were reimbursed for each service provided, to a managed care model in which providers received a capitated fee intended to cover all services provided to a covered child. By 2016, 39 states had made the switch from Medicaid managed care (MMC) to FFS. ${ }^{2}$ There are several features of MMC which might lead to an increase in diagnoses and treatment of chronic conditions.

First, children may gain access to providers under MMC. For example, children who did not have a primary care physician would be assigned one under MMC. Second, insurers often receive a higher capitated fee for a child with a disability. The intent of these "riskadjustment" payments is to encourage managed care plans to enroll all children rather than "cream-skim" by enrolling only healthy children. However, the higher payments may also create incentives to increase diagnoses of disability.

Third, MMC providers are subject to regular reporting requirements for a number of quality measures. While FFS providers are subject to similar requirements, it may be easier for the state to monitor a handful of insurers who contract with the state to provide MMC services than to monitor a large number of individual providers. One important quality measure involves requirements for timely preventive screening of children. More screening is likely to result in more diagnosed cases of childhood disability, other things being equal.

\footnotetext{
${ }_{1}$ MEPS asks whether children took particular medications. The NSCH incidence numbers are in response to questions about whether a child was ever diagnosed with a particular condition, whether a child has it currently, and whether a child is currently taking medication. Our work will focus on whether the child is currently being treated with medications for a condition.

${ }^{2}$ Kaiser Foundation Medicaid Managed Care Market Tracker Tool for March 2016 data point (https://www.kff.org/medicaid/stateindicator/total-medicaid-mcos/?currentTimeframe $=3 \&$ sortModel $=\% 7 \mathrm{~B} \% 22$ colId $\% 22: \% 22$ Location $\% 22, \% 22$ sort $\% 22: \% 22$ asc $\% 22 \% 7 \mathrm{D})$
} 
We investigate these issues using a $60 \%$ random sample of all children who were on Medicaid in South Carolina (SC) at any time during the period of 2004-2015. Our sample focuses on children under 17, and the claims data are matched to birth certificate records in order to obtain more nuanced background information about the children.

We rely on variation in MMC enrollments created by changes in South Carolina's Medicaid program, as well as rich panel data which allow us to follow the same child before and after the mandated switch to MMC. Between October 2007 and May 2008, South Carolina changed the "default" plan type for an enrollee from FFS to a MMC plan, which resulted in a sharp increase in MMC enrollments. ${ }^{3}$ In 2013, a number of FFS primary care case management plans were converted to MMC, which again sharply increased MMC enrollments.

In models with child fixed effects, we find that the transition to MMC increased the probability of being treated for ADHD by $11.6 \%$ and increased the number of children being treated for asthma by $8.2 \%$. These estimates in turn suggest that the switch to MMC can explain $38.2 \%$ of the $30.4 \%$ increase in the probability of being diagnosed with ADHD and $22.5 \%$ of the $36.4 \%$ increase in asthma caseloads over our sample period.

The evidence indicates that increases in access to primary care, additional screenings, and the incentives created by risk adjustment all played a role in increasing asthma and ADHD caseloads, along with the treatment of many other conditions. In fact, these explanations are not mutually exclusive because the incentives created by risk adjustment reinforce explicit incentives to increase screening, which in turn is facilitated by greater access. We find that children are $16.2 \%$ more likely to have had a well-child visit, and approximately $20.7 \%$ more likely to have received a developmental screening, as well as $40.7 \%$ more likely to have received a hearing test, and $21.2 \%$ more likely to have received vaccinations. There is also some evidence that children are more likely to be prescribed medications that lead to a higher risk adjustment weight. The child's individual weight in the risk adjustment formula goes up by $17.4 \%$ under MMC, and about half of this increase is accounted for by increases in the treatment of ADHD and asthma.

Finally, we ask whether the increase in treatment is accompanied by changes in child health. We find no change in hospitalizations, increases in office visits for sickness, and increases in emergency room (ER) visits for preventable, non-preventable, and non-urgent conditions. These patterns may reflect gatekeeping by MMCs since fewer children were able to obtain an appointment with a specialist. They may also reflect difficulty accessing primary care physicians for care beyond the annual well-child visit.

The number of ER visits for primary-care preventable conditions increased by $7.2 \%$ overall, while the number of visits for asthma, in particular, increased by $11.3 \%$. This larger increase in asthma visits could be driven by poor adherence to medication in that we see that although MMC increases the proportion of children who were ever treated for asthma and

\footnotetext{
${ }^{3}$ This change was part of the "Healthy Connections Choices" program which was rolled out in the Midlands in October 2007, followed by the Piedmont in January 2008, the Lowcountry in March 2008, and the Pee Dee in May 2008.
} 
who fill prescriptions covering over three months, the rate at which children do so remains low at $11.5 \%$.

We cannot say whether these large and striking changes in patterns of utilization reflect changes in underlying health, but they are certainly not consistent with improvements in the efficiency of the care provided under the Medicaid program. If, on the one hand, the increase in ER visits is borne by children who are sicker, then that would suggest that they are not getting necessary preventive care (despite the increases in well-child visits and screenings). If, on the other hand, children are not sicker but using the ER more, then the efficiency of MMC could be improved by shifting children to less expensive providers.

The paper is organized as follows. The background Section 2 introduces the data and outlines the relevant features and changes in the SC Medicaid program as well as important features of ADHD and asthma and their treatment. Section 3 provides an overview of the empirical strategy. Section 4 describes our results and Section 5 provides a discussion and conclusions.

\section{Data and background}

Medicaid is organized as a federal-state matching grant program. Under federal regulations, states have some scope to set income eligibility guidelines, define services, and to set payments for providers in the Medicaid program. As discussed above, one of the largest changes in the Medicaid program in recent years has been the switch from fee-for-service Medicaid to Medicaid managed care. The switch was motivated by a desire to contain costs, but also by the idea that managed care would involve more care coordination and possibly better health outcomes.

MMC plans are reimbursed a fixed amount (the capitated payment) for each enrollee per month of enrollment. ${ }^{4}$ The base fee depends on patient characteristics including age, sex (in some age groups), and Medicaid qualifying category. Capitated payments create an incentive for "cream skimming," that is for plans to seek out healthy patients within a group and to try to steer sicker, more expensive ones elsewhere. This incentive to avoid costly patients has been shown to be important. For example, Glied et al. (1997) highlight incentives for selecting patients, and Currie and Fahr (2005) and Kuziemko et al. (2013) show that in the absence of risk-adjustment, insurers use observable characteristics such as race to avoid high risk patients.

Researchers have also investigated the effects of the switch to MMC on state Medicaid costs. For instance, Duggan (2004) and Duggan and Hayford (2013) show that switching from FFS to MMC actually increased state Medicaid costs, either because savings due to preventive care were not realized or because people increased their reliance on more expensive forms of care such as emergency rooms.

\footnotetext{
${ }^{4}$ Two previous studies (Bokhari et al. (2005) and Conrad (2005)) have suggested that capitation might encourage the use of stimulant medications for ADHD because it is cheaper than therapy. However, in South Carolina, behavioral therapy is "carved out" of MMC plans in our sample period, which means that plans are not responsible for the cost of such therapy and this type of cost incentive for promoting the use of stimulant medication is not present.
} 
The question of whether MMC affects the types of specific treatments received less attention from researchers. An exception is Turner (2015) who asks how the switch to MMC affected the treatment of mental health. She uses managed care penetration rates at the eligibility group-county-year level as an instrument for individual's plan type using data from three states. Such county-level instruments do not completely solve the selection problem given that managed care plans can choose which counties to operate in, and might choose to avoid counties with higher numbers of patients with poor health, other things being equal. Turner finds that diagnoses of mental health fell by $30 \%$ while drug treatment for mental health problems increased by $9 \%$. These contradictory findings may reflect imperfect diagnoses data in the national Medicaid claims data. ${ }^{5}$

Our analysis is based on a $60 \%$ random sample of all South Carolina Medicaid enrollees under 17 years of age who were enrolled at some point in time over the period from 2005 to 2015. There are 577,209 individuals and 2,960,843 child-year observations. ${ }^{6}$ The data we have available are comprised of a claims data base with information about all of the medical services a child received including inpatient, outpatient, ER, hospitalization, and prescription drugs, and a file with the enrollment status of every child in every month, regardless of whether they received any services or filled prescriptions. ${ }^{7}$ For children born after 1993, we merge the SC Medicaid claims data with the SC birth certificate (Vital Statistics) data which have additional information about maternal characteristics at the time of the birth. ${ }^{8}$

The South Carolina Medicaid program, both under FFS and MMC, provides inpatient, outpatient, and pharmaceutical coverage to all enrollees. Children under 21 years old are not subject to copays for either drugs or doctor visits, though in both FFS and MMC, they must find a provider who participates in the Medicaid program. There are virtually no ADHD or asthma drugs that are excluded from the formulary and no limits on the number of prescriptions filled.

Prior to 2007, SC Medicaid operated a predominantly FFS system. In 2007, the state began a two pronged effort to increase enrollments in MMC. First, the state began defaulting new enrollees and people whose eligibility was up for renewal into MMC (Madalena and Tester, 2010). Fig. 3 shows the dramatic increase in the fraction of the Medicaid caseload enrolled in MMC after 2007. There is also a sharp increase in enrollment in 2013 which corresponds to the conversion of primary care case management (PCCM) networks to risk-based managed care providers. These PCCM plans were operated on a FFS basis, with providers receiving an additional fee for providing case management services. They were phased out largely because there did not seem to be any difference in performance between PCCM

\footnotetext{
5 In particular, in some states, doctor visits seem to be under-reported relative to prescriptions in the data that are reported to the federal government which could lead diagnoses to be under-reported.

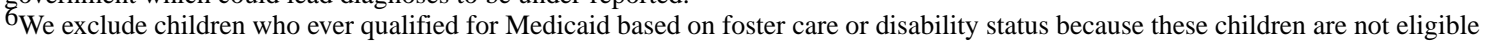
for MMC.

${ }^{7}$ Claims include information on primary and secondary diagnoses, procedure codes (Current Procedural Terminology Codes or CPT), dates of service, the Medicaid plan type, payment amounts, and basic information about the provider. An unusual and important feature of these claims data is that we have detailed information about both FFS and MMC providers (rather than observing only the capitated MMC payment).

${ }^{8}$ These data are collected from maternal and hospital worksheets a few days after birth and come from the SC Department of Health and Environmental Control. They provide information about a child's health at birth, and the mother's basic demographic information including level of schooling.
} 
plans and other FFS providers even though PCCMs were more expensive to the government given the additional case management fee. With the conversion to MMC, these plans became subject to all the regulations governing risk-based MMC plans, as described further in Section 2.2 below.

Since it was not possible to enroll people in MMC in areas that were not served by plans, the state also made a concerted effort to increase the number and geographic coverage of MMC plans. ${ }^{9}$ However, the fact remains that MMC was not rolled out randomly across the states. Counties that already had managed care plans with adequate provider networks, and who were willing to participate in the Medicaid program entered first, and the residents of these counties may have differed from those of other counties with lower MMC penetration. Fig. 4 shows the distribution of MMC enrollments across counties in various sample years, showing the general tendency towards higher enrollments over time but also the wide geographic variation across SC at a point in time over most of the sample period.

In South Carolina, two additional changes occurred over our sample period that might be expected to have effects on the composition of the caseload. First, income cutoffs were raised from 150\% of the federal poverty level (FPL) to 200\% in 2008 and 208\% in 2014. (The main effect of the Affordable Care Act on the eligibility of children was to mandate the use of Modified Adjusted Gross Income (MAGI) methodology for determining Medicaid eligibility which is what raised the income eligibility threshold from 200 to $208 \%$ of FPL.)

Second, in 2011, South Carolina launched an initiative to use administrative data from other welfare programs to identify families who were eligible for Medicaid. This initiative, called Express Lane Eligibility, also streamlined the re-enrollment processes.

As a result of these changes, Medicaid enrollment in South Carolina grew over our sample period, as shown in Fig. 3. To the extent that the composition of the Medicaid caseload was changing over time in a way that would be expected to alter asthma and ADHD caseloads, such changes could complicate our interpretation of the effects of the switch within Medicaid from FFS to MMC.

Table 1 provides an overview of the Medicaid caseload in each year. Over time, there is a trend towards a younger age of first enrollment, while the total number of years enrolled and the months enrolled in the year show no clear trend. Table 1 shows that among households with a positive monthly income, income approximately doubled. However, the fraction of the caseload with zero countable incomes also almost doubled. The fraction of children who were African-American fell from 52.3\% to $45.3 \%$ and the fraction of Hispanics increased correspondingly over time. The children's mean birth weight stayed approximately constant, and the fraction of mothers with some college increased slightly over time. It is notable that there was little "churn" in our caseload in the sense that most children were enrolled 7-9 years (only $8.5 \%$ of the sample children had any gaps in their Medicaid coverage). On

\footnotetext{
${ }^{9}$ In regressions that included enrollee characteristics, county fixed effects and year fixed effects, we found that the probability of being enrolled in MMC for at least one month went up by 2.6 percentage points with each additional plan available. In 2003, two counties had no MMC plan, while the rest had one plan. By 2008, one county had three plans, six had five plans, twelve had six plans, and the remaining 27 counties had seven plans. By 2012, all counties had converged to four plans.
} 
average, a child was enrolled for 10.2 months in a year, but given a two-month grace period, most children who are ever in our Medicaid data base are covered for 12 months of every year. ${ }^{10}$

Table 2 attempts to assess the likely effect of these changes in the composition of the caseload on rates of asthma and ADHD. ${ }^{11}$ We first used data from 2004 to 2005 to estimate the prevalence of ADHD and asthma as a function of observed characteristics including gender, race, age, birth month, enrollment category, monthly family income, county, birth weight, mother's age at birth, and mother's education at the time of the birth. We then used the estimated coefficients to predict ADHD and asthma rates for each year from 2006 to 2015. Table 2 also shows the actual rates of ADHD and asthma observed in our data in each year.

Table 2 suggests that very little of the observed increase in ADHD can be predicted using changes in the sample composition. For asthma, the changes in sample composition actually predict a fall in the rate rather than the observed increase, which is consistent with a relatively more advantaged population being drawn into care by the expansions. We conclude that changes in the composition of the caseload are unlikely to be responsible for the increasing rates of asthma and ADHD that we observe.

In order to account for the possibility of unobservable differences in patient characteristics, we will estimate models of the effects of MMC that include child-specific fixed effects, as described further below. Table 1A examines the characteristics of this sample of "changing" children compared to the samples of children who were either always in MMC or always in FFS. The majority of children in our sample experienced the transition to MMC, with the second largest category being those who were always in MMC. The sample of "changers" is somewhat different from the non-changers: The children tend to have been enrolled longer and from a younger age, the mothers are less educated, and the fraction Hispanic is a little greater, for example.

To summarize some key advantages of our data and context: First, we have a large panel data set that allows us to use "switchers" to try to identify the effects of managed care on individual children. Second, we have very detailed claims data with the diagnoses and treatments that were used to calculate reimbursement rates for managed care plans. Third, we can use the detailed data to try to examine mechanisms such as greater screening, upcoding, or improvements in health that might underlie any changes in treatment that we see with managed care adoption.

\footnotetext{
${ }^{10}$ Appendix A Table A1 shows the equivalent numbers for children who are first-time enrollees. These new enrollees come from a somewhat more advantaged part of the population, at least by the end of the period. It is important to note that "old" enrollees were also subject to the MMC mandates at their annual re-enrollments.

${ }^{11}$ There are two possible ways to measure prevalence in our data. We can follow the SC risk-adjustment model and count only people who took medication prescribed for these conditions. Or we can also include diagnoses. In practice, the rates are almost identical for ADHD (6.1 vs. $6.2 \%$ of children), and a little lower for asthma if we include only children who are medicated (16.4 vs. $15.4 \%$ of children). In this paper we follow the SC government practice and use medication use to measure prevalence, but the results using diagnoses plus medication are quite similar as shown in Appendix A Table A2.
} 


\subsection{Important features of MMC contracts}

In this section, we describe three key features of MMC contracts that could impact the diagnosis and treatment of childhood chronic conditions including asthma and ADHD. These features are a responsibility to ensure access to providers; risk adjusted compensation mechanisms; and quality of care requirements (in particular, the provision of health screenings).

Each MMC plan contracts with the state and the terms specify the counties where they will provide services. Insurers are required to show that they have an adequate network of providers in a county. In particular, they must show that there is at least one primary care provider available to serve patients within a 30-mile radius of the patient's address and assign the patient to a particular provider. MMC plans are also required to accept new patients who present themselves and to provide referrals to specialists and hospitals if necessary. Furthermore, plans often require PCPs to contact new enrollees and see them for an initial office visit and assessment within the first 90 days of enrollment (e.g. see WellCare Medicaid provider manual, 2015). A higher number of plans in a county is associated with a greater willingness of physicians to participate in managed care (Ly and Glied, 2014; Dafny et al., 2012). Hence, higher MMC enrollments might increase access to preventive care such as well-child visits and immunizations.

As discussed above, MMC plans have an incentive to try to select relatively healthy enrollees. In order to combat this tendency, the state began to apply risk-adjustment to capitation rates starting in 2009. The base capitated fee is calculated every year by an actuarial firm hired by the state based on the claims experience in previous years for enrollees in the same category. At the beginning of each month, an insurer receives the negotiated base capitated fee.

At the end of the year, all the claims submitted to the SC Department of Health and Human Services (DHHS) are run through the risk adjustment model to determine the number of plan enrollees who filled at least one prescription for drug classes that are specified in the model.

Risk adjustment in South Carolina Medicaid is based on the prescription drugs taken by enrollees, not diagnoses. The argument underlying this choice is that prescriptions may be more accurately reported and less subject to gaming than diagnoses. ${ }^{12}$ Each drug class has a weight that reflects the additional cost of treating a child with that condition. Each enrollee's score is the sum of these additional weights and the base weight for their group. Risk adjustment weights are applied over the entire experience of a plan with a given child during her enrollment in that year. The average score is then calculated for every plan. Plans that have higher average enrollee scores have their base capitation rate bumped up retroactively for their pool of enrollees, while the plans with the healthiest enrollees by these criteria may see a retroactive reduction in their capitation rate. For example, in the last two years of our

\footnotetext{
${ }^{12}$ South Carolina uses "Restricted Medicaid Rx Model," (MRx) developed by the University of California San Diego (UCSD) (http:// medicaidrx.ucsd.edu/). The MRx model is one of several different risk adjustment methods that are used by state Medicaid programs across the country. See the web site for a complete list of weights.
} 
data, two out of six insurers received a $4 \%$ rate bump in both years, while the lowest ranked plan received a $7 \%$ reduction in capitated fees.

Fig. 5 provides anecdotal evidence that MMC plans devote considerable attention and resources to encouraging providers to properly code all of a child's medical conditions. As the information on the Blue Cross-Blue Shield (BCBS) website suggests, insurers offer monthly webinars, newsletters and bulletins, monthly regional workshops, direct support, monthly "Gaps in Care" reports, provider report cards, and on-site visits aimed at encouraging providers to code correctly. BCBS of South Carolina also has an internal system that rates providers based on how many patients are treated according to the guidelines and how the provider compares to other providers in his or her locality, with monetary rewards at stake (a physician recognition program). Other insurers have similar programs.

Risk adjustment creates an incentive for providers to diagnose and prescribe medications for ADHD, asthma, and other conditions. Whether or not it is attractive to increase diagnoses of a particular condition will depend on the cost of screening for the condition, the probability of finding the condition if the child is screened, how costly it is to treat that condition, and the expected future cost of not treating it. As we will argue below, ADHD and asthma are diseases with characteristics that may make them particularly attractive targets for additional screening and diagnosis under this risk adjustment system.

A third component of MMC that encourages the diagnosis and treatment of childhood chronic conditions is mandated screening for such conditions. In principle, all children in the Medicaid program are entitled to Early and Periodic Screening, Diagnostic and Treatment (EPSDT) benefits and states must cover a broad array of preventive services. The SC Department of Health and Human Services specifies that Medicaid children are to receive all screenings according to the American Academy of Pediatrics schedule. In practice, however, rates of screening are low in most jurisdictions. For example, in our sample overall, only $43.9 \%$ of Medicaid children received a general health screening each year.

MMC plans are required to have written procedures for notifying, tracking, and following up eligible children. In order to improve compliance, plans are allowed to provide incentives to members at their own expense, such as monetary rewards and prepaid gift cards. For example, one of the SC MMC plans, WellCare, offers enrollees a \$20 reward for completing annual child health check-ups. WellCare also sends providers lists of children who are noncompliant. They assess primary care providers' adherence to EPSDT tracking and follow-up guidelines via random audits and require poor performers to implement corrective action plans. The BCBS BlueChoice Medicaid Health Plan urges providers to use their Gaps in Care Reports to identify patients in need of well-child visits and pays an additional $\$ 30$ for each well-child visit provided. These examples suggest that MMC plans take the screening requirements seriously, perhaps because they are required to submit quality data, including information on EPSDT compliance, to the state.

These performance data feed into performance measures, compensation, ranking, and enrollment auto-assignment mechanisms. A part of the capitation fee is withheld if 
performance falls below the required minimum, and the undistributed funds are re-allocated to providers above the 75th percentile on quality measures. If a plan does not achieve the National Medicaid 25th percentile for any quality measure, it has to submit a corrective action plan and may be subject to liquidated damages of $\$ 250,000$ for each unmet measure. In 2012, South Carolina withheld 1\% from capitation fees and allowed MMC plans that improved their quality measures by one standard deviation on 10 measures to receive a bonus payment. In 2013, the amount withheld was $1.5 \%$ and improvement was required for 16 measures. Other things being equal, we would expect these incentives to increase screening, and the increased screening should lead to more diagnoses of childhood chronic conditions.

\subsection{Characteristics of ADHD and asthma}

ADHD is a neurological condition defined by persistent symptoms of inattention and/or hyperactivity-impulsivity. It is one of the most common mental health disorders affecting school-aged children. Asthma is a chronic inflammation of the airways in the lungs. It is one of the most common physical chronic childhood illnesses, and the most frequent cause of childhood ER visits and hospitalizations.

While ADHD and asthma are quite different disorders, they do share certain similarities. First, they affect large numbers of children, suggesting that greater screening is likely to turn up additional cases. Second, diagnosis is often difficult. For ADHD, there is no fully "objective" test to determine whether a child has the condition or not. The diagnostic criterion states that a child with ADHD must have had at least six of the symptoms for six months or more to a degree that is maladaptive and inconsistent with the child's developmental level. The symptoms must also be present in two or more settings.

For asthma, physicians can conduct a test of lung capacity using a spirometer, but this test is difficult to do in young children. Testing is not straightforward in older children and teens either and is not always performed. For example, Murray et al. (2017) discuss the absence of gold standard tests of the condition, with most guidelines concurring that "asthma is a clinical diagnosis based on a characteristic pattern of symptoms and signs in the absence of an alternative explanation." 13 In practice, it is often difficult to distinguish the symptoms of asthma (including wheezing, coughing, chest tightness, and breathlessness) from other respiratory conditions such as allergies, influenza, or bronchitis.

A third common feature is that medication is the first-line treatment for both conditions. The vast majority of children diagnosed with ADHD receive medication, with some also receiving behavioral therapies. Many studies have shown short-term improvements in attention and decreases in disruptive behavior in medicated children, though the longer-term effects of medication for ADHD are more controversial (Scheffler et al., 2009; Visser et al., 2014; Currie et al., 2014; Dalsgaard et al., 2014; Chorniy and Kitashima, 2016; Kitashima and Chorniy, 2017).

\footnotetext{
${ }^{13}$ Aaron et al. (2017) finds that in a Canadian cohort of 613 adults with a recent diagnosis of asthma, extensive testing ruled out the diagnosis in a third of those assessed. Despite of the possibility of performing formal tests, many physicians rely on symptoms in the absence of alternative explanations, rather than objective medical tests (Cave and Atkinson, 2014; Murray et al., 2017).
} 
Asthma is managed by avoiding triggers and using medications for both long-term control and for the immediate relief of symptoms. Children who adhere to their medication regime are much less likely to experience asthma symptoms or to need care in ERs or hospitals (Donahue et al., 1997; Adams et al., 2001). ${ }^{14}$ Early asthma treatment is also thought to prevent the development of irreversible airway obstruction (Agertoft and Pedersen, 1994).

A fourth characteristic of both ADHD and asthma is that medications for these conditions are often prescribed by general practitioners, and general practitioners seem to feel confident in their ability to diagnose and treat these conditions. Davis et al. (2012) survey primary care pediatricians in Kentucky and find that $98.5 \%$ respondents report being comfortable diagnosing ADHD and $100 \%$ feel comfortable treating it. To provide some context, out of these same respondents only $41.5 \%$ feel comfortable diagnosing eating disorders (with $21.5 \%$ comfortable treating them) and only $69.2 \%$ are comfortable diagnosing autism (with $41.5 \%$ comfortable treating it). All of the respondents reported encountering ADHD patients at least monthly, with all other conditions trailing behind. Finally, these doctors are confident of their ability to treat ADHD even though only $10 \%$ of the survey respondents believed that they were "well prepared" by their residency program to either diagnose or treat behavioral or mental health problems. Anderson et al. (2015) analyze 2008-2011 MEPS data and find that $42 \%$ of ADHD children only see a primary care provider. In contrast, $83 \%$ of children with anxiety or mood disorders were referred to a mental health specialist.

A fifth point of commonality between asthma and ADHD is that untreated, both conditions can lead to severe consequences. Asthma is a cause of about 2 million child emergency room visits each year and 439,000 child hospitalizations. In extreme cases, it can result in death. Children suffering from ADHD face behavioral, learning, developmental and emotional problems that extend into adulthood. Currie and Stabile (2006) find a large negative effect of ADHD on children's academic test scores and schooling attainment, while Fletcher and Wolfe (2009) and Fletcher (2014) report a higher probability of engaging in criminal behavior as well as lower employment probabilities, wages, and higher accident probabilities. Although research is ongoing, the bulk of the evidence suggests that ADHD medication affects behavior in a way that may improve safety and health outcomes, although there is little evidence of long-term improvements in academic performance with drug treatment.

In summary, both ADHD and asthma are conditions with features that may make increases in diagnosis and treatment likely given the provider incentives created by MMC. They are common, so that additional screening is likely to uncover undiagnosed cases. They are difficult to definitively diagnose, but paradoxically, frequently diagnosed and treated by nonspecialists. They are straightforward to treat in that the first-line treatment in both cases involves the prescription of common medications which are widely viewed as safe and which receive a positive weight in the MRx risk adjustment model used in many states, including South Carolina. And finally, the consequences of missing a serious case could be

\footnotetext{
${ }^{14}$ The most common medications used for long-term control of asthma are inhaled corticosteroids, which should be used daily to reduce the reactivity of airways and prevent attacks.
} 
severe for the affected individual, leading providers to wish to err on the side of being aggressive about diagnosis and treatment.

\section{Methods}

We wish to estimate the effect of MMC enrollment on the probability that a child is diagnosed and treated for asthma or ADHD, and on the probability that they receive different types of care. Hence, the main equation of interest is:

$$
D_{\text {ict }}=\alpha \text { Managed } \text { care }_{\text {ict }}+\mathrm{X}_{\text {ict }} \beta+\mu_{\text {county }}+\mu_{\text {year }}+\varepsilon_{\text {ict }}
$$

where for individual $\mathrm{i}$, in county c, at time t, $D_{\text {ict }}$ represents the probability of being diagnosed and/or treated for asthma or ADHD; Managedcare ict $_{\text {is }}$ is equal to 1 if an individual is enrolled in MMC for at least one month in year $\mathrm{t}$ and is zero otherwise; $\boldsymbol{X}_{i c t}$ is a vector of individual and family characteristics including the child's gender, race, birth month, child age and maternal age (single year of age dummies), birth weight (<1500 g, 1500-2499 g, 2500-2999 g, 3000-3499 g, 3500-3999 g, 4000-4999 g, >=4500 g) maternal education category ( $<9,9-11$, high school diploma, some college, college plus, missing), Medicaid enrollment category and monthly family income (\$0, \$200, \$200-399...). Mother characteristics are collected at the child's birth from the birth certificates. Medicaid enrollment categories and family income are recorded annually, as a part of the enrollment renewal process. We include county $\left(\mu_{\text {county }}\right)$ and year $\left(\mu_{\text {year }}\right)$ fixed effects in all specifications to control for county and year-level determinants of diagnosis and treatment rates. All standard errors are clustered at the county level, in order to allow for correlations between outcomes of children within the same county.

As discussed above, although families had little choice about being defaulted into MMC, there might be systematic unobserved differences between children in locations with greater MMC penetration and other children. In order to capture these differences we also estimate child fixed effects models:

$$
D_{\text {ict }}=\alpha \text { Manage dcare }{ }_{i c t}+\mathrm{X}_{i c t} \beta+\mu_{\text {county }}+\mu_{\text {year }}+\mu_{\text {patient }}+\varepsilon_{i c t}
$$

where $\mu_{\text {patient }}$ is the child fixed effect and the other variables are defined as above.

A key contribution of this paper is that given the richness of our data we are able to go beyond simply asking whether MMC has an effect on diagnosis and treatment and investigate the mechanisms underlying this effect. We estimate a series of regressions examining the role of several features of the managed care model: risk adjustment mechanism, screening requirements, and access to care, in driving our results about the effects of MMC.

In order to evaluate the role of risk adjustment, we estimate models of the same form as (1) and (2) using the following dependent variables: The child's individual weight in the MRx model; and the child's individual weight excluding drugs prescribed for ADHD or asthma. A 
comparison of these two outcomes helps us to measure how much of any observed upweighting of the child is accounted for by asthma and ADHD alone.

In order to examine access to care and screening, we look for procedures that indicate that screening or preventive procedures took place. These include well-child visits, blood work, developmental screening, hearing tests, and vaccinations.

Asthma is a condition that can lead to acute health emergencies, and thus these emergencies should be less likely to occur if someone is properly diagnosed and treated. We examine hospital stays and ER visits for asthma, as well as for asthma-related diseases including upper respiratory infections (URI). And because we find that MMC is associated with increases in hospitalizations and ER visits for asthma, we also conduct a deeper look at the type of medications that are being prescribed for asthma when patients switch to MMC, asking whether new patients are more likely to receive long-acting preventive drugs or shortterm acute response drugs.

Finally, given previous evidence that treatment for ADHD can reduce ER visits and hospitalization for injuries (Chorniy and Kitashima, 2016; Dalsgaard et al., 2014) we also examine the effect of MMC on these outcomes.

\section{Estimation results}

Prior to discussing our regression analyses, it is useful to set the stage with some "event study" graphs. Fig. 6 shows three graphs, constructed using point estimates and confidence intervals from regressions with county FEs, year FEs, and all available controls for the individuals who switched from FFS to MMC in 2007 or later and who were in the sample for at least 2 years prior to the switch and for two years post-switch. Time zero is the year that the child made the switch from FFS to MMC (which could have occurred at any point during that year). There are 409,230 observations representing 81,846 patients.

The figures show a clear increase in the probability of treatment for ADHD after a child switched to MMC. The evidence for asthma is also suggestive of an increase, but slightly less clear, with treatment rising after the switch, but then falling back subsequently, suggesting perhaps a lack of continuity in newly prescribed drug treatments (a hypothesis we investigate further below). The third figure shows a large increase in well-child screenings following the switch to MMC, which offers a possible mechanism for the increase in diagnoses. These figures suggest that MMC had significant effects on treatment, which we now analyze in a regression context.

Table 3 shows the estimated effect of being defaulted into MMC on the probability of being treated not only for ADHD and asthma, but for any of the conditions with prevalence over $1 \%$ in our data. ${ }^{15}$ We first show OLS estimates without controls in column (1) followed by regressions with a full set of controls in column (2) and estimates with child fixed effects in column (3). A comparison across columns suggests that there are characteristics of the children which are not captured in the administrative data but which do affect the estimated

\footnotetext{
15 Estimates using prescriptions plus diagnoses are very similar to those using only prescriptions, as shown in Appendix A Table A2.
} 
impact of MMC. The child fixed effects estimates are generally smaller than the OLS estimates with or without controls, though this is not always the case.

The table also lists the MRx weights associated with the various conditions. That is, as discussed above, if a child is prescribed medications for a condition, then the child will get a higher weight in the risk adjustment calculation applied to each insurer at the end of the year. The estimates suggest increases in treatment for all of the common conditions listed in Table 3, regardless of the condition weight. For example, the child fixed effects estimates imply that the probability of being treated for low severity infections increases by $12.8 \%$ although that is a zero weight condition, compared to an increase of $11.6 \%$ for ADHD and $8.2 \%$ for asthma which have weights of 0.777 and 0.322 , respectively.

We can also examine the effect of MMC on the weight associated with the child in the risk adjustment, keeping in mind that other things being equal, being treated with more conditions, or more serious conditions, will result in a higher weight. Table 4 shows that MMC is associated with an increase in the risk adjustment weight of 0.020 on a baseline of 0.115 , or $17.4 \%$. The second panel of Table 4 indicates that a little under half of this increase in weights is due to ADHD and asthma, which follows from the combination of relatively high weights and high prevalence for these two conditions.

Table 5 explores the effect of MMC on access to care in doctors' offices and to the various types of screening activities that we can observe in the claims data. The estimates imply that being enrolled in MMC increases the probability that a child received a well-child visit in the past twelve months by $16.2 \%$. Turning to some of the individual screening activities that might take place during a well-child visit, we see a $12.3 \%$ increase in the probability of blood work; a $20.7 \%$ increase in the probability that the child is assessed using a developmental screen (from a very low baseline of $2.9 \%$ ); an $40.7 \%$ increase in the probability of a hearing screen; and a $21.2 \%$ increase in the probability that the child received any vaccinations. ${ }^{16}$

These findings suggest that the switch to MMC could have had a large effect on diagnoses through the mechanism of increased access to care and screenings. If for example, the true incidence of ADHD was 6.6\%, and the true incidence of asthma was $16.4 \%$ (our measured maximum annual rates from Table 2), and all well-child visits resulted in appropriate screening for children who would have been undiagnosed previously, then the $16.2 \%$ increase in well-child visits could potentially increase diagnoses of ADHD by $0.211 \mathrm{pp}$ $\left((6.6-5.3)^{*} 0.162\right)$ and diagnoses of asthma by $0.421 \mathrm{pp}((16.4-13.8) * 0.162)$ relative to 2004 baseline rates. These calculations suggest that increases in screenings could translate into 4.0\% more ADHD cases and 3.1\% more asthma cases, relative to the 2004 baselines, which can be compared to the actual percentage increases of 30.4 and 36.4 for ADHD and asthma, respectively.

\footnotetext{
16 Unfortunately, it is difficult to determine whether the child is up to date on their immunizations because the records usually do not say what vaccine or a combination of vaccines was administered. This common limitation in claims data can make it difficult to assess provider compliance with mandated vaccination schedules.
} 
If MMC is helping children in need of care to access necessary services then one might hope that increases in diagnosis and treatment would result in fewer sick visits to physicians, although it is also possible that sick visits could increase with access. The impact of MMC on sick visits is shown in the last three panels of Table 5 which show that sick visits also increased. The magnitude of the increase in sick visits is similar to the increase in well visits, though since the base is higher for sick visits, it represents a smaller percentage increase. Sick visits to mental health professionals also increase with access to MMC, which is relevant to ADHD treatment. However, sick visits to other specialists decline, perhaps reflecting non-participation of these specialists in the MMC networks. It is important to note that mental health was "carved out" of the managed care contract, which means that it was covered on a FFS basis even for children in managed care (managed care companies were therefore not responsible for paying for outpatient and inpatient mental health visits until July 2016). Managed care did have to pay for all other specialists.

Table 6 considers hospitalizations. One would hope that children who needed to be hospitalized would be hospitalized under both FFS and MMC Medicaid. Table 6 shows that although in the raw data children on MMC were less likely to be hospitalized, this is an artifact of selection. There is in fact no difference in the probability of hospitalization once either controls or child specific fixed effects are included in the models, and this is true for both hospitalizations that could be preventable through primary care (such as those for asthma) and those that are non-preventable. ${ }^{17}$

Table 7 examines ER visits. In addition to examining the total number of visits, we follow Billings et al. (2000) and examine the categories of ER visits based on the patient's diagnostic codes including: non-urgent ER visits (e.g. sore throat); PC-treatable (e.g. ear infection); PC-preventable (e.g. asthma attack); Non-preventable visits (e.g. a cardiac dysrhythmia); Injuries; and other. ${ }^{18}$ Table 7 indicates that there was an overall increase of $7.68 \%$ in the use of the ER when children gained MMC. It appears that much of this increase was for visits that were either preventable through adequate primary care (the increase in asthma visits is particularly large at $11.30 \%$ ), or that could have been treated in an office setting.

These estimates suggest that patients either don't have convenient access to primary care or prefer to use the ER rather than their assigned primary care physician, who might be located as far as thirty miles away from their home or might have long wait times. Note that unlike most patients with private insurance, Medicaid patients had no co-pays for using the ER under either FFS or MMC. This increased reliance on ERs for routine care likely drove up costs for the state Medicaid programs, consistent with the results of Duggan (2004) and Duggan and Hayford (2013). In the short run, the reliance on ERs would have been costly to

\footnotetext{
${ }^{17}$ Hospitalizations are classified as either preventable or non-primary care preventable following Lu and Kuo (2012). According to their classification, potentially preventable hospitalizations include those for asthma, bacterial pneumonia, diabetes, immunization preventable conditions, and others. Respiratory conditions comprised the largest share of potentially preventable pediatric hospitalizations. We use the ICD9/10 condition codes provided by Lu and Kuo (2012) and identify claims with these conditions as a primary diagnosis on hospital claims as "preventable." Since hospitalizations are a relatively rare outcome, logits (rather than linear probability models) are shown in Appendix A Table A3. The findings are similar.

${ }^{18}$ Because patients may have multiple diagnosis codes, it is possible for the number of visits of each sub-type to add up to more than the total number of visits.
} 
insurers as well, although higher costs in year $\mathrm{t}$ got rolled into higher capitation rates in $\mathrm{t}$ +1 , given the state funding formula.

Table 8 focuses on treatment of asthma in a sample of children who received medication for asthma at least once over the sample period in an effort to assess the continuity of care as an indicator of its quality. The first two panels examine the impact of MMC on the probability that children on Medicaid received either three or more (Panel A) or six or more (Panel B) 30-day prescriptions for asthma in a given year. Effective asthma control would have required a child to continuously take corticosteroid medication. We see, however, that among these children only a small minority receives three or more prescriptions in a year, and an even smaller number receive six or more. These percentages both rise modestly with MMC, but remain low suggesting that many children are not being treated effectively.

Generally, asthma patients require both a long-acting steroid medication which reduces the likelihood of an asthma attack, and a short-acting asthma attack medication. Panels C and D of Table 8 examine the effects of MMC on the types of medication taken. They show that MMC was associated with increases in the number of children who were prescribed only long-acting medications, or only short-acting asthma attack medications in the past 12 months. Both of these patterns suggest improper treatment of asthma or compliance with treatment which could possibly be a factor in the increasing ER asthma visits. ${ }^{19}$

\section{Discussion and conclusions}

Increasing rates of chronic conditions among children are a grave concern, and also a puzzle given that other health indicators such as mortality have shown great improvement, and underlying causes, such as smoking and pollution, have been declining (Currie and Schwandt, 2016). This study focuses on two of the most common serious childhood chronic conditions, ADHD and asthma, and suggests that some of the increase in the incidence of these conditions may be explained by increases in screening, access to care, and incentives to treat created by Medicaid managed care.

Starting from the observation that in national data, the rise of these conditions appears to be occurring mainly among children on Medicaid, we document a remarkable finding, which is that in the South Carolina Medicaid caseload, about a third of the increase in ADHD and asthma over the period from 2004 to 2015 can be attributed to the switch to from fee-forservice to Medicaid managed care. By 2016, 39 states were contracting with managed care organizations to cover Medicaid recipients, suggesting that the switch from FFS to MMC may be driving changes in caseloads in other states as well (Paradise, 2015).

We focus on three aspects of risk-based managed care systems which may jointly have contributed to increases in the treatment of asthma and ADHD. First, managed care may improve access to care. Second, through the risk adjustment mechanism, MMC creates

\footnotetext{
${ }^{19}$ A possibility that cannot be investigated using our data is that patients are not receiving sufficient education in how to use their medications properly. Inhalers require some basic training to be used correctly and it is "well documented that patients can have problems adopting the correct inhaler technique and thus receiving adequate medication" (Price et al., 2012). Sestini et al. (2006) report that many doctors are unfamiliar with the characteristics of the available inhalers and have only limited ability to guide patients in their usage.
} 
incentives to treat children for conditions that increase a child's weight in the risk adjustment formula. In the methodology adopted by South Carolina, children are "counted" in the weighting formula only if they receive a prescription, and hence, there is an incentive to write at least one prescription for a condition with an added weight, but less incentive to ensure follow through on medication compliance. Third, both because of these financial incentives and because of quality control mechanisms, MMC may increase screening for chronic conditions, which, other things being equal, would be expected to yield more cases.

Our estimates suggest that all of these forces are likely to be at work. MMC increases the probability that a child received a well-child visit by $16.2 \%$, and we see increases in the probability of having blood work, developmental and hearing screens, and vaccinations. We also see a $17.4 \%$ increase in the child's individual risk adjustment weight, with roughly half of the increase in the weight being accounted for by asthma and ADHD alone.

To summarize these results, the actual increases in ADHD and asthma caseloads were 30.4\% and $36.4 \%$ respectively. We calculate that the switch to MMC increased caseloads for these two conditions by $11.6 \%$ (ADHD) and $8.2 \%$ (asthma). An estimate of the possible effect of increased screening alone is $4.0 \%$ (ADHD) and 3.1\% (asthma).

In principle, increases in treatment could improve health outcomes, if children who lacked access to care gained access under MMC. Unfortunately, we find little evidence that this is the case. We do not find any statistically significant effect on hospitalizations, and we find increases in all categories of ER visits. A large part of the increase in preventable ER visits is driven by asthma, and we see that relatively few children with asthma appeared to be using medications appropriately, both before and after MMC.

While managed care plans improved access to primary care physicians and ensured that a larger share of Medicaid enrollees benefitted from preventive care, other features of the program apparently backfired. First, although more children received at least one prescription for medication, providers had little incentive to follow up about adherence. Second, access to primary care seems to have changed in a way that encouraged reliance on emergency rooms for even non-urgent care. It is possible that some of this shift to ERs reflected a loss of access to specialist care (for all specialties except mental health).

We cannot say whether these large and striking changes in patterns of utilization reflect any change in underlying child health, but they are certainly not consistent with improvements in the quality and efficiency of the care provided under the Medicaid program. These patterns suggest that patients in MMC may have experienced difficulties accessing primary care outside of the annual well-child visit.

Children on Medicaid are among the most vulnerable patient populations. Our results indicate that their care is sensitive to the incentives provided by the reimbursement system. The switch to MMC plans in South Carolina was associated with more screening and more treatment of the two most common childhood chronic conditions: ADHD and asthma. However, the switch to MMC does not seem to have resulted in an increase in the quality of care the children received, judged using the metrics of preventable hospitalizations, ER 
visits, and compliance with recommended medication regimes. Further research into the disappointing results in terms of health care utilization is warranted.

\section{Acknowledgments}

We thank Genevieve Kenney, Dan Miller, Tom Mroz, Gaurav Sabharwal, David Silver, Amanda Starc, Tom Vogl, Florence Watts, participants at 2016 ASHEcon and 2017 AEA (HERO) meetings and seminar participants at Harvard University, Notre Dame University, and Princeton's Center for Health and Wellbeing for their helpful feedback on the project. We are also grateful to the Center for Health and Wellbeing for financial support. Finally, we would like to express our gratitude to SC RFA and DHHS for their help and patience with our data requests. In particular, we thank Chris Finney, Joe Magagnoli, Sarah Crawford, Muhammad Salaam, and Julius Covington.

\section{References}

Aaron SD, Vandemheen KL, FitzGerald JM, Ainslie M, Gupta S, Lemière C, Field SK, McIvor RA, Hernandez P, Mayers I, Mulpuru S. Reevaluation of diagnosis in adults with physician-diagnosed asthma. JAMA. 2017; 317(3):269-279. [PubMed: 28114551]

Adams RJ, Fuhlbrigge A, Finkelstein JA, Lozano P, Livingston JM, Weiss KB, Weiss ST. Impact of inhaled anti-inflammatory therapy on hospitalization and emergency department visits for children with asthma? Pediatrics. 2001; 107(4):706-711. [PubMed: 11335748]

Agertoft L, Pedersen S. Effects of long-term treatment with an inhaled corticosteroid on growth and pulmonary function in asthmatic children? Respir Med. 1994; 88(5):373-381. [PubMed: 8036306]

Anderson L ElizabethChen Minghua L, Perrin James M, Van Cleave Jeanne. Outpatient visits and medication prescribing for US children with mental health conditions. Pediatrics. 2015; 136(5): 1178-1185. (2015). [PubMed: 26598457]

Billings J, Parikh N, Mijanovich T. Emergency Room Use: The New York Story. The Commonwealth Fund; New York, NY: 2000. (Issue Brief No. 434)

Bokhari F, Mayes R, Scheffler RM. An analysis of the significant variation in psychostimulant use across the U.S. Pharmacoepidemiol. Drug Saf. 2005; 14:267-275.

Centers for Disease Control. National Surveillance of Asthma: United States, 2001-2010, Series 3 \#35. National Center for Health Statistics; Hyattsville, MD: 2012 Nov.

Cave A, Atkinson L. Asthma in preschool children: a review of the diagnostic challenges. J Am Board Fam Med. 2014; 27(4):538-548. [PubMed: 25002008]

Chorniy A, Kitashima L. Sex, drugs, and ADHD: the effects of ADHD pharmacological treatment on teens' risky behaviors. Labour Econ. 2016; 43:87-105.

Conrad P. The shifting engines of medicalization. J Health Soc Behav. 2005; 46(1):3-14. [PubMed: 15869117]

Currie J, Fahr J. Medicaid managed care: effects on children's Medicaid coverage and utilization? J Public Econ. 2005; 89(1):85-108.

Currie J, Schwandt H. Mortality inequality: the good news from a county-level approach. J Econ Perspect. 2016; 30(2):29-52. [PubMed: 27917023]

Currie J, Stabile M. Child mental health and human capital accumulation: the case of ADHD? J Health Econ. 2006; 25(6):1094-1118. [PubMed: 16730082]

Currie J, Stabile M, Jones L. Do stimulant medications improve educational and behavioral outcomes for children with ADHD. J Health Econ. 2014; 37:58-69. [PubMed: 24954077]

Dafny LeemoreDuggan MarkRamanarayanan Subramaniam. Paying a premium on your premium. Consol US Health Insur Ind. 2012; 102(2):1161-1185.

Dalsgaard S, Nielsen HS, Simonsen M. Consequences of ADHD medication use for children's outcomes. J Health Econ. 2014; 37:137-151. [PubMed: 24997381]

Davis DW, Honaker SM, Jones VF, Williams PG, Stocker F, Martin E. Identification and management of behavioral/mental health problems in primary care pediatrics: perceived strengths, challenges, and new delivery models. Clin Pediatr. 2012; 51(10):978-982.

Donahue JG, Weiss ST, Livingston JM, Goetsch MA, Greineder DK, Platt R. Inhaled steroids and the risk of hospitalization for asthma? J Am Med Assoc. 1997; 277(11):887-891. 
Duggan M, Hayford T. Has the shift to managed care reduced medicaid expenditures? Evidence from state and local-level mandates. J Policy Anal Manage. 2013; 32(3):505-535. [PubMed: 23814802]

Duggan M. Does contracting out increase the efficiency of government programs? Evidence from Medicaid HMOs. J Public Econ. 2004; 88(12):2549-2572.

Fletcher J, Wolfe B. Long-term consequences of childhood ADHD on criminal. J Mental Health Policy Econ. 2009; 12(3):119.

Fletcher JM. The effects of childhood ADHD on adult labor market outcomes? Health Econ. 2014; 23(2):159-181. [PubMed: 23427026]

Glied S, Sisk J, Gorman S, Ganz M. National Bureau of Economic Research Working Paper No. 6164. 1997 Sep. Selection, Marketing, and Medicaid Managed Care.

Kitashima L, Chorniy A. Princeton University Working Paper. 2017 May. ADHD Medication Effects on Primary and Secondary Students' Academic Achievement.

Kuziemko I, Meckel K, Rossin-Slater M. Evidence from Medicaid and Implications for Health Reform (No. w19198). National Bureau of Economic Research; 2013. Do Insurers Risk-select Against Each Other?.

Lu SamKuo Dennis Z. Hospital charges of potentially preventable pediatric hospitalizations. Acad Pediatr. 2012; 12(5):436-444. [PubMed: 22922047]

Ly DP, Glied SA. The impact of managed care contracting on physicians? J Gen Intern Med. 2014; 29(1):237-242. [PubMed: 24002628]

Madalena Michael A, Tester Robin E. Report to South Carolina Department of Health and Human Services Proviso 21.33-Medicaid Cost and Quality Effectiveness. 2010. http:// www.scstatehouse.gov/Archives/DHHS/MedicaidCostandQualityEffectiveness.pdf

Murray C, Foden P, Lowe L, Durrington H, Custovic A, Simpson A. Diagnosis of asthma in symptomatic children based on measures of lung function: an analysis of data from a populationbased birth cohort study. Lancet Child Adolesc Health. 2017; 1(2):114-123. [PubMed: 29034296]

Paradise Julia. Medicaid Moving Forward. Kaiser Family Foundation; 2015. (Issue Brief, March 9)

Price D, Chrystyn H, Kaplan A, Haughney J, Román-Rodríguez M, Burden A, Chisholm A, Hillyer EV, von Ziegenweidt J, Ali M, van der Molen T. Effectiveness of same versus mixed asthma inhaler devices: a retrospective observational study in primary care. Allergy, Asthma Immunol Res. 2012; 4(4):184-191. [PubMed: 22754711]

Scheffler RM, Brown TT, Fulton BD, Hinshaw SP, Levine P, Stone S. Positive association between attention-deficit/hyperactivity disorder medication use and academic achievement during elementary school. Pediatrics. 2009; 123(5):1273-1279. [PubMed: 19403491]

Sestini PiersanteCappiello VitaAliani MariaMartucci PaolaSena AngeloVaghi AdrianoAldo PieroCanessa MargheritaMelani Andrea S. Prescription bias and factors associated with improper use of inhalers. J Aerosol Med. 2006; 19(2):127-136. [PubMed: 16796537]

Turner Lesley J. The effect of medicaid policies on the diagnosis and treatment of children's mental health problems in primary care. Health Econ. 2015; 24(2):142-157. [PubMed: 24123653]

Visser SN, Danielson ML, Bitsko RH, Holbrook JR, Kogan MD, Ghandour RM, Perou R, Blumberg SJ. Trends in the parent-report of health care provider-diagnosed and medicated attention-deficit/ hyperactivity disorder: United states, 2003-2011. J Am Acad Child Adolesc Psychiatry. 2014; 53(1):46.

WellCare of South Carolina, Inc. [Accessed on 1 September 2017] Medicaid Provider Manual. 2015. https://www.wellcare.com/en/South-Carolina/Providers/Medicaid

\section{Appendix A}

\section{Table A1}

SC Medicaid Sample Population Characteristics. First-time enrollees (since 2004).

\begin{tabular}{lllllll}
\hline Characteristics & 2004 & 2006 & 2008 & 2010 & 2012 & 2014 \\
\hline Medicaid enrollment characteristics
\end{tabular}




\begin{tabular}{|c|c|c|c|c|c|c|}
\hline Characteristics & 2004 & 2006 & 2008 & 2010 & 2012 & 2014 \\
\hline Age 1 st enrolled & & 2.8 & 2.6 & 2.8 & 3.9 & 3.4 \\
\hline Years enrolled & & 7.2 & 6.3 & 5.0 & 3.6 & 2.0 \\
\hline Months enrolled in year & & 6.5 & 6.4 & 6.5 & 5.9 & 6.6 \\
\hline \multicolumn{7}{|l|}{ Family net income } \\
\hline Monthly income, if $>0$ & & $1,015.9$ & $1,146.8$ & $1,244.7$ & $1,417.2$ & $2,141.7$ \\
\hline Missing, $\%$ & & $2.6 \%$ & $2.5 \%$ & $2.6 \%$ & $7.1 \%$ & $1.8 \%$ \\
\hline Zero, \% & & $63.2 \%$ & $58.0 \%$ & $57.9 \%$ & $72.8 \%$ & $77.1 \%$ \\
\hline \multicolumn{7}{|l|}{ Demographics } \\
\hline Male & & $50.6 \%$ & $50.4 \%$ & $49.9 \%$ & $50.0 \%$ & $50.8 \%$ \\
\hline Age & & 2.8 & 2.6 & 2.8 & 3.9 & 3.4 \\
\hline Race: White & & $43.4 \%$ & $43.1 \%$ & $46.2 \%$ & $48.0 \%$ & $48.5 \%$ \\
\hline Black & & $41.2 \%$ & $39.4 \%$ & $37.5 \%$ & $38.5 \%$ & $37.0 \%$ \\
\hline Hispanic & & $12.1 \%$ & $13.5 \%$ & $10.9 \%$ & $8.4 \%$ & $8.6 \%$ \\
\hline $\mathrm{N}$ obs. & & 32,733 & 33,885 & 33,078 & 38,616 & 38,412 \\
\hline \multicolumn{7}{|l|}{ Birth certificate data } \\
\hline Birth weight, g & & 3179 & 3195 & 3202 & 3218 & 3227 \\
\hline Mother's age & & 24.2 & 24.4 & 25.0 & 25.6 & 26.3 \\
\hline School: Elem & & $6.2 \%$ & $6.2 \%$ & $5.0 \%$ & $3.3 \%$ & $3.2 \%$ \\
\hline High school & & $27.5 \%$ & $25.7 \%$ & $22.9 \%$ & $19.1 \%$ & $16.4 \%$ \\
\hline High school diploma & & $34.7 \%$ & $34.2 \%$ & $33.1 \%$ & $32.7 \%$ & $31.1 \%$ \\
\hline Some college & & $23.3 \%$ & $24.6 \%$ & $26.8 \%$ & $29.9 \%$ & $30.4 \%$ \\
\hline College diploma & & $8.4 \%$ & $9.3 \%$ & $12.2 \%$ & $15.1 \%$ & $19.0 \%$ \\
\hline $\mathrm{N}$ obs. & & 22,869 & 23,647 & 23,331 & 24,402 & 23,766 \\
\hline
\end{tabular}

Notes: The table is based on a 60\% random sample of SC Medicaid population under 17 years old in 2004-2015, excluding children in foster care and disabled children. Birth certificates data are available for in-state births for children born after 1992. These records are matched to Medicaid records on name, date of birth, race, gender, and hospital of birth, when available. Note that the later they enroll, the fewer years they will appear in our sample.

\section{Table A2}

Estimates of the Effect of MMC on ADHD and Asthma Diagnoses or Prescriptions.

\begin{tabular}{|c|c|c|c|c|}
\hline & (1) & (2) & (3) & (4) \\
\hline County; Year Fixed Effects & NO & YES & YES & $\%$ change from (3) \\
\hline Controls (incl. b.cert.) & NO & YES & YES & \\
\hline Child Fixed Effects & NO & NO & YES & \\
\hline \multicolumn{5}{|c|}{ Panel A: The Effect of MMC on ADHD } \\
\hline Child in MMC & $\begin{array}{l}0.014 * * * \\
(0.002)\end{array}$ & $\begin{array}{l}0.011 * * * \\
(0.001)\end{array}$ & $\begin{array}{l}0.008 * * * \\
(0.0004)\end{array}$ & $11.1 \%$ \\
\hline Mean outcome & 0.072 & & & \\
\hline \multicolumn{5}{|c|}{ Panel B: The Effect of MMC on Asthma } \\
\hline Child in MMC & $\begin{array}{l}0.042 * * * \\
(0.003)\end{array}$ & $\begin{array}{l}0.026 * * * \\
(0.003)\end{array}$ & $\begin{array}{l}0.017 * * * \\
(0.0006)\end{array}$ & $10.4 \%$ \\
\hline Mean outcome & 0.164 & & & \\
\hline
\end{tabular}

Notes: There are 2,960,843 observations. Controls include the child's gender, race, birth month, child and maternal age (single year of age dummies), birth weight ( $<1500 \mathrm{~g}, 1500-2499 \mathrm{~g}, 2500-2999 \mathrm{~g}, 3000-3499 \mathrm{~g} . . .>=4500 \mathrm{~g}$ ), maternal 
education ( $<12,12$, some college, college plus, missing), Medicaid enrollment category, and monthly family income ( $\$ 200$, $\$ 200-399, \ldots$.). Standard errors are clustered at the county level. In specification (3) controls include time-variant characteristics (income and age) and standard errors are clustered on patients.

\section{Table A3}

Logit functional form for hospitalizations.

\begin{tabular}{llll}
\hline & $(\mathbf{1})$ & $(\mathbf{2})$ & $(3)$ \\
\hline County and Year Fixed Effects & NO & YES & YES \\
Controls (incl. b.cert.) & NO & YES & YES \\
Child Fixed Effects & NO & NO & YES \\
Panel A: The Effect of MMC on Probability of Any Hospitalizations for Preventable Conditions & & 0.0280 \\
& $-0.2138^{* * *}$ & $0.0522 * *$ & $(0.0239)$ \\
Mean outcome & $(0.0397)$ & $(0.0247)$ & \\
Panel B: The Effect of MMC on Probability Of Any Hospitalization for non PC-Preventable Conditions \\
Child in MMC & 0.007 & 0.0178 & 0.0188 \\
Mean outcome & $-0.2513 * * *$ & $(0.0215)$ & $(0.0190)$ \\
\hline
\end{tabular}

See notes to Table 6 . 


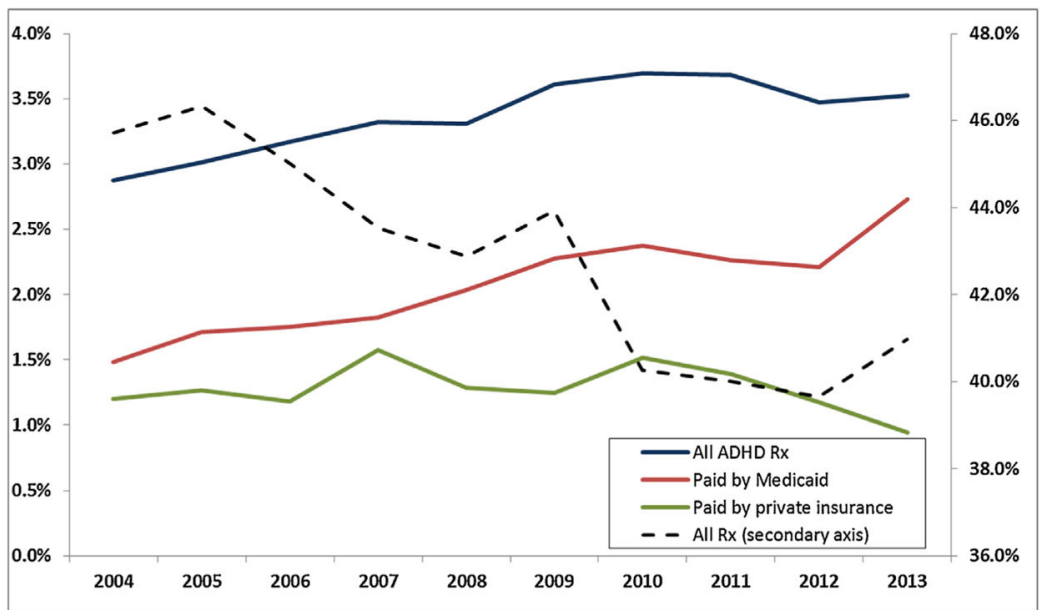

Fig. 1.

Nationwide trends in filled ADHD prescriptions.

Notes: Data source: Medical Expenditures Panel Survey (MEPS), 2004-2013. The sample includes all ADHD prescriptions filled by children under 17 years old. 


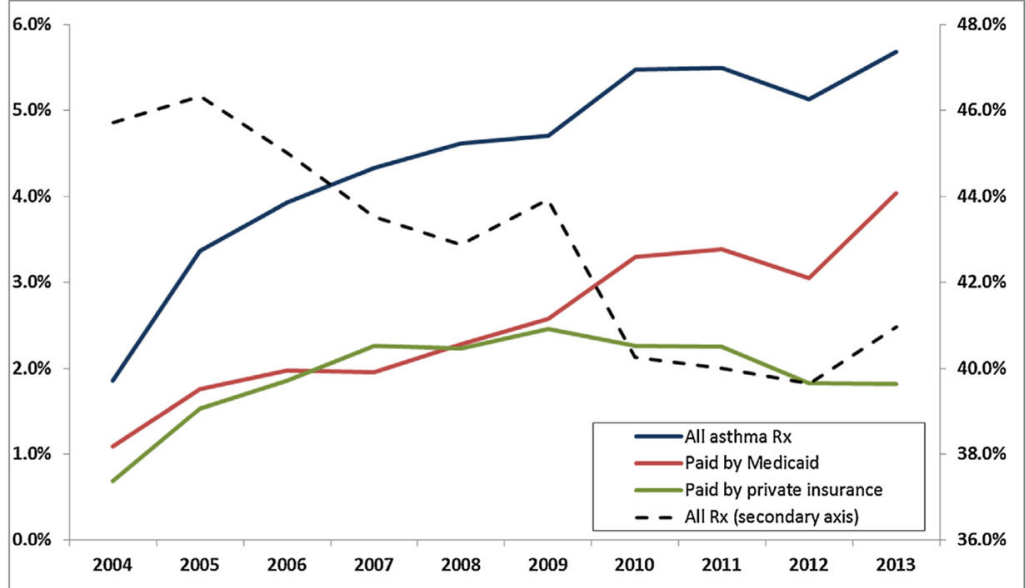

Fig. 2.

Nationwide trends in filled asthma prescriptions.

Notes: Data source: Medical Expenditures Panel Survey (MEPS), 2004-2013. The sample includes all asthma prescriptions filled by children under 17 years old. 


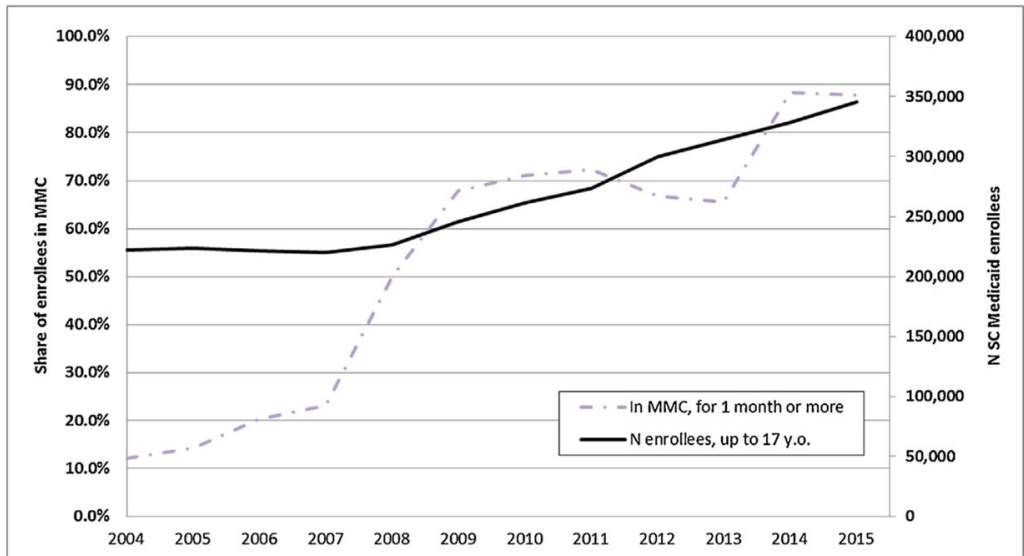

Fig. 3.

Share of SC Medicaid enrollees in Medicaid managed care (MMC).

Notes: Data source: SC Medicaid, 2004-2015. The enrollment figures are based on monthly enrollment information of patients up to 17 years old. 'MMC' stands for Medicaid managed care. The number of enrollees (solid line) is depicted using the secondary, right-hand side axis. 


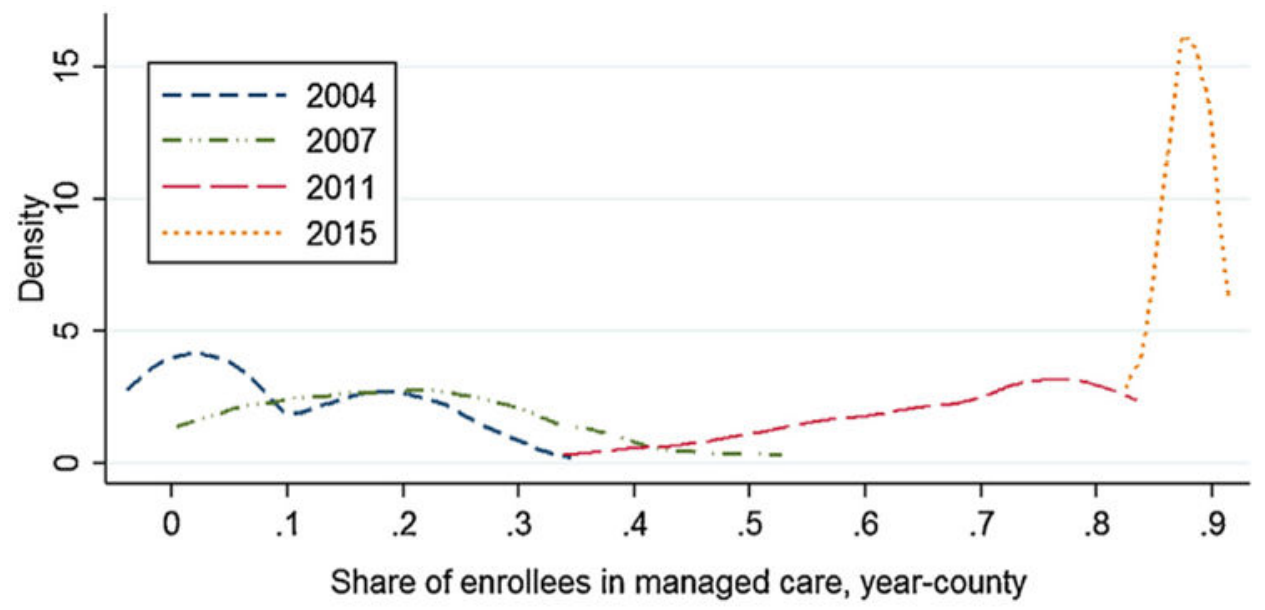

Fig. 4.

Distribution of counties by share of SC Medicaid enrollees in MMC.

Notes: Data source: SC Medicaid, 2004-2015. The enrollment figures are based on monthly enrollment information of patients under 17 years old. "MMC" stands for Medicaid managed care. 


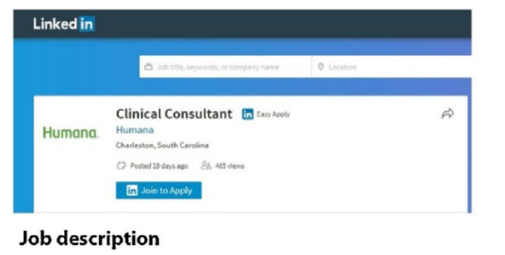

Job description

Humana is seeking a Clinical Consultant to bridge gaps in care for all lines of business and work with providers to close HEDIS gaps while EMR capability improves, and progress toward all Stars program achievement.

- Analysis and subsequent work on ensuring accurate and complete documentation and coding of open conditions with provider

- Requires clinical expertise (and possibly field coding) - Majority of time is external facing representing Humana with provider partners

- Clinical coding (related to Stars, such as (PTII), clinical, project management, communication/education, quality improvement

Role Essentials

- Working knowledge of STARS,CAHPS and HOS - Working knowledge of Medicare Risk Adjustment - Ability to build strong relationships, identify risk. remove barriers and improve clinical outcomes and the member experience

- Strong presentation skills, with the ability to communicate and effectively present to all levels internal and external to the organization. in

\section{UHG}

Manager of HEDIS and Risk Adjustment Charleston

UnitedHealth Group North, SC, us

Job description

The Manager of HEDIS and Risk Adjustment will be responsible for working directly with providers in a consultative approach to ensure that they are utilizing highly specific codes.This will be accomplished through coding education and chart review.

\section{Primary responsibilities}

- Target local providers who would benefit from our Medical Risk Adjustment\& HEDIS / STARS training

- Contact physicians, medical groups, IPAs and hospitals, and build positive, consultative relationships

- Educate providers on how to improve their Risk Adjustment Factor (RAF) scores and Stars ratings, which measure their patients' health status - Collaborate with doctors, coders, facility staff and a variety of internal and external personnel on a wide scope of Risk Adjustment \& HEDIS education efforts

- Conducts onsite physician chart audits (including research and presentation) and identifies potential suspects through clinical documentation where diagnosis is clinically indicated but not documented

diagnosis is clinically indicated but not documented - Assess and interpret whether the coding assigned by the provider was properly assigned based upon review of the medical documentation and application of the coding guidelines

Fig. 5.

Sample job postings for a managerial position at insurance companies that provide managed care plans.

Notes: These job advertisements have been accessed on April 20th, 2017 using LinkedIn search tool. Selected categories describing the positions are included. 


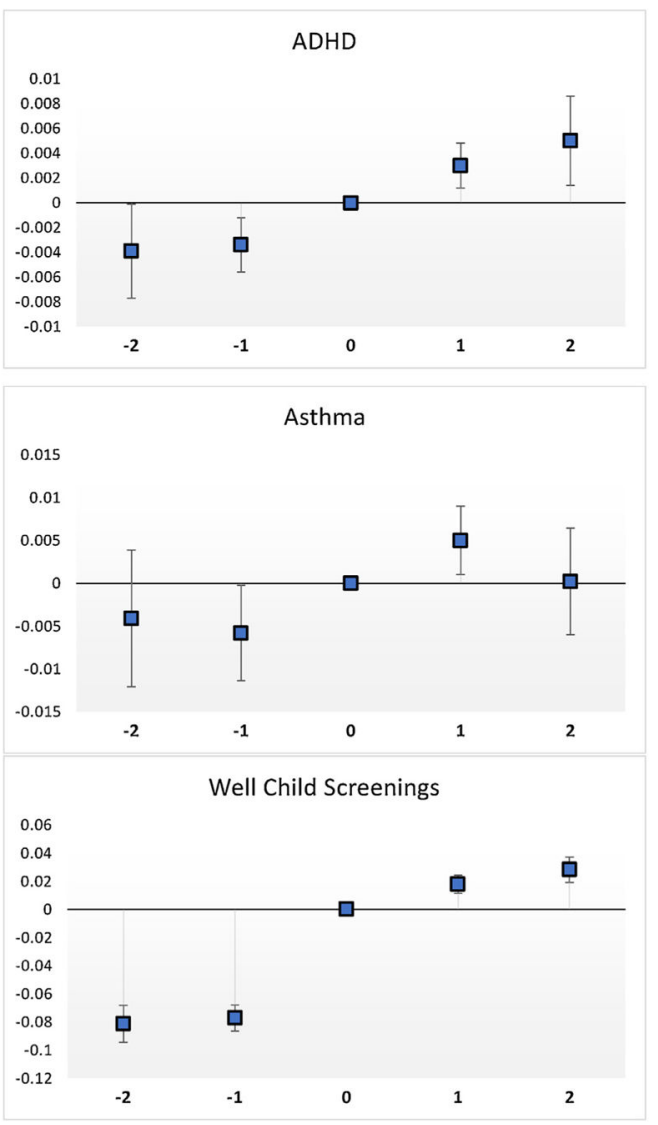

Fig. 6.

Event study Graphs.

Notes: These graphs are constructed using point estimates and confidence intervals from regressions for each outcome with county FEs, year FEs, and all available controls for the individuals who switched from FFS to MMC in 2007 or later and remained in the sample for at least 2 years prior to the switch and post-switch. There are 409,230 observations. 


\section{Table 1A}

Characteristics by Whether Transitioned to MMC.

\begin{tabular}{|c|c|c|c|}
\hline Characteristics & Never MMC & Always MMC & Change MMC \\
\hline \multicolumn{4}{|c|}{ Medicaid enrollment characteristics } \\
\hline Age 1st enrolled & 4.3 & 1.8 & 1.2 \\
\hline Years enrolled & 5.1 & 5.9 & 9.2 \\
\hline Months enrolled in year & 8.8 & 10.2 & 10.5 \\
\hline \multicolumn{4}{|c|}{ Family net income, mean over months in sample } \\
\hline Monthly income, if >0, \$2015 & $1,196.7$ & $1,358.7$ & $1,246.8$ \\
\hline Missing, \% & $5.3 \%$ & $3.1 \%$ & $5.3 \%$ \\
\hline Zero, $\%$ & $53.7 \%$ & $47.7 \%$ & $38.9 \%$ \\
\hline \multicolumn{4}{|l|}{ Demographics } \\
\hline Male & $52.4 \%$ & $50.1 \%$ & $50.4 \%$ \\
\hline Age & 8.9 & 5.1 & 7.3 \\
\hline Race: White & $48.8 \%$ & $38.2 \%$ & $39.8 \%$ \\
\hline Black & $40.4 \%$ & $50.3 \%$ & $48.0 \%$ \\
\hline Hispanic & $7.3 \%$ & $7.6 \%$ & $9.7 \%$ \\
\hline N obs. & 341,445 & 634,583 & $1,984,815$ \\
\hline $\mathrm{N}$ children & 135,248 & 167,997 & 273,964 \\
\hline \multicolumn{4}{|l|}{ Birth certificate data } \\
\hline Birth weight, g & 3221 & 3174 & 3181 \\
\hline Mother's age & 24.4 & 24.4 & 23.7 \\
\hline School: Elem & $4.6 \%$ & $4.0 \%$ & $5.8 \%$ \\
\hline High school & $24.7 \%$ & $26.4 \%$ & $30.9 \%$ \\
\hline High school diploma & $41.8 \%$ & $37.7 \%$ & $40.2 \%$ \\
\hline Some college & $19.1 \%$ & $22.5 \%$ & $16.8 \%$ \\
\hline College diploma & $9.8 \%$ & $9.3 \%$ & $6.4 \%$ \\
\hline $\mathrm{N}$ obs. & 125,364 & 257,333 & $1,30,9,827$ \\
\hline $\mathrm{N}$ children & 54,572 & 103,890 & 209,607 \\
\hline
\end{tabular}

Notes: The table is based on a 60\% random sample of SC Medicaid population under 17 years old in 2004-2015, excluding children in foster care and disabled children. Birth certificates data are available for in-state births for children born after 1992. These records are matched to Medicaid records on name, date of birth, race, gender, and hospital of birth, when available. Years enrolled referes to years in the sample if they are enrolled in a given year while months enrolled refers to the current year. 


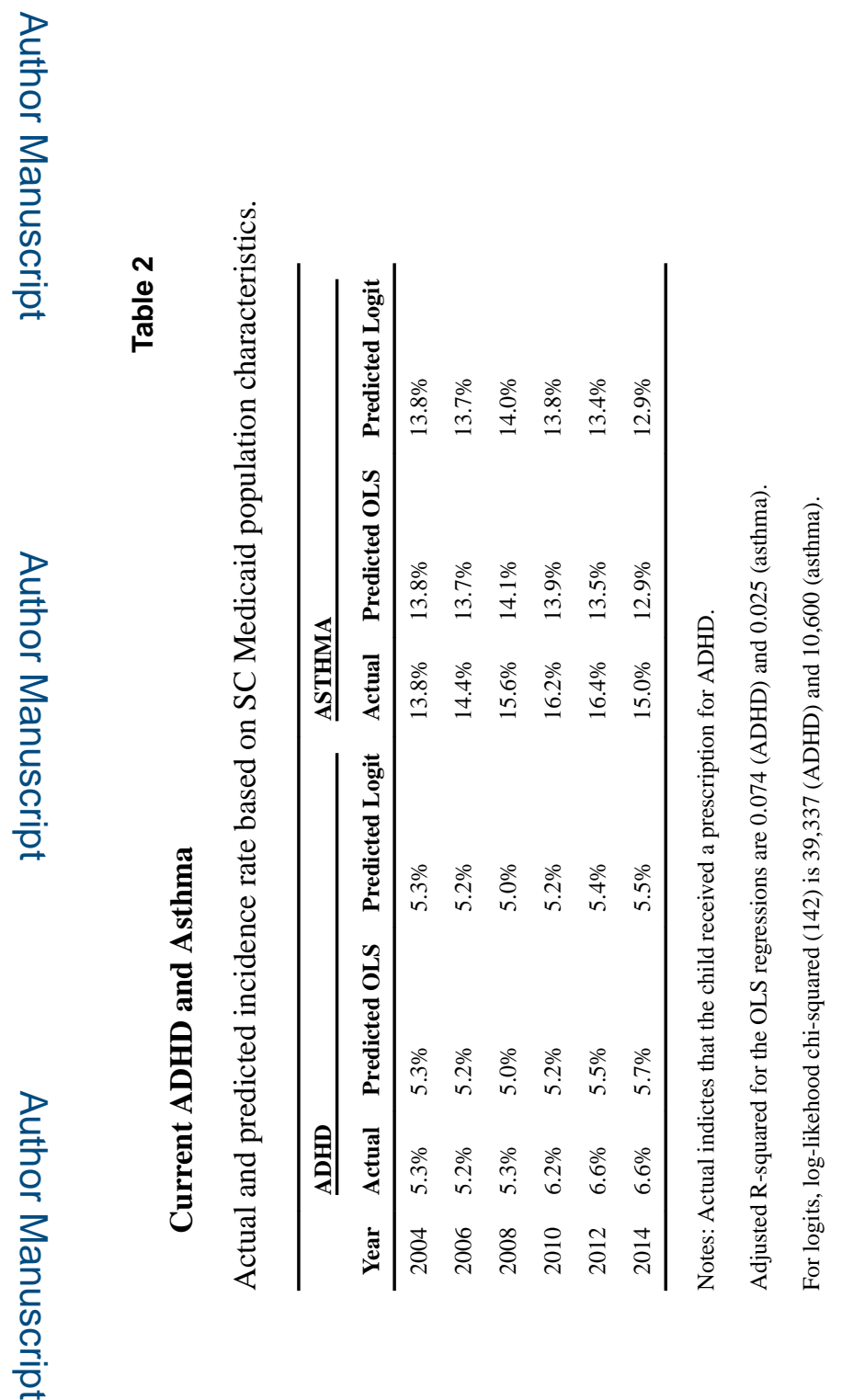


Table 3

Estimates of the Effect of MMC on Prescriptions in the MRx model.

\begin{tabular}{|c|c|c|c|c|}
\hline & (1) & (2) & (3) & (4) \\
\hline County; Year Fixed Effects & NO & YES & YES & $\%$ change from (3) \\
\hline Controls (incl. b.cert.) & NO & YES & YES & \\
\hline Child Fixed Effects & NO & NO & YES & \\
\hline \multicolumn{5}{|c|}{ Panel A: The Effect of MMC on ADHD, MRX weight $=0.777$} \\
\hline Child in MMC & $\begin{array}{l}0.0096^{* * * *} \\
(0.0020)\end{array}$ & $\begin{array}{l}0.0086^{* * * *} \\
(0.0014)\end{array}$ & $\begin{array}{l}0.0071 * * * \\
(0.0004)\end{array}$ & $11.60 \%$ \\
\hline Mean outcome & 0.061 & & & \\
\hline \multicolumn{5}{|c|}{ Panel B: The Effect of MMC on Asthma, MRx weight $=0.322$} \\
\hline Child in MMC & $\begin{array}{l}0.0224 * * * \\
(0.0026)\end{array}$ & $\begin{array}{l}0.0206^{* * *} * \\
(0.0028)\end{array}$ & $\begin{array}{l}0.0126 * * * \\
(0.0006)\end{array}$ & $8.20 \%$ \\
\hline Mean outcome & 0.154 & & & \\
\hline \multicolumn{5}{|c|}{ Panel C: The Effect of MMC on Infections, Low Severity, MRX weight $=0.0$} \\
\hline Child in MMC & $\begin{array}{l}0.0338^{* * * *} \\
(0.0055)\end{array}$ & $\begin{array}{l}0.0654 * * * \\
(0.0048)\end{array}$ & $\begin{array}{l}0.0472 * * * \\
(0.0009)\end{array}$ & $12.80 \%$ \\
\hline Mean outcome & 0.369 & & & \\
\hline \multicolumn{5}{|c|}{ Panel D: The Effect of MMC on Infections, Medium Severity, MRx weight $=0.137$} \\
\hline Child in MMC & $\begin{array}{l}-0.0001 \\
(0.0043)\end{array}$ & $\begin{array}{l}0.0212 * * * \\
(0.0032)\end{array}$ & $\begin{array}{l}0.0158 * * * \\
(0.0007)\end{array}$ & $8.80 \%$ \\
\hline Mean outcome & 0.180 & & & \\
\hline \multicolumn{5}{|c|}{ Panel E: The Effect of MMC on Eye, Ear, Nose and Throat, MRx weight $=0.151$} \\
\hline Child in MMC & $\begin{array}{l}0.0216^{* * * *} \\
(0.0032)\end{array}$ & $\begin{array}{l}0.0282 * * * \\
(0.0033)\end{array}$ & $\begin{array}{l}0.0174 * * * \\
(0.0007)\end{array}$ & $5.80 \%$ \\
\hline Mean outcome & 0.172 & & & \\
\hline \multicolumn{5}{|c|}{ Panel F: The Effect of MMC on Inflammatory/Autoimmune, $M R x$ weight $=0.156$} \\
\hline Child in MMC & $\begin{array}{l}0.0187 * * * \\
(0.0028)\end{array}$ & $\begin{array}{l}0.0142 * * * \\
(0.0016)\end{array}$ & $\begin{array}{l}0.0090 * * * \\
(0.0005)\end{array}$ & $8.60 \%$ \\
\hline Mean outcome & 0.105 & & & \\
\hline \multicolumn{5}{|c|}{ Panel G: The Effect of MMC on Pain, MRX weight $=0.0$} \\
\hline Child in MMC & $\begin{array}{l}-0.0063^{* * * *} \\
(0.0015)\end{array}$ & $\begin{array}{l}0.0065^{* * *} \\
(0.0008)\end{array}$ & $\begin{array}{l}0.0056 * * * \\
(0.0004)\end{array}$ & $10.40 \%$ \\
\hline Mean outcome & 0.054 & & & \\
\hline \multicolumn{5}{|c|}{ Panel H: The Effect of MMC on Gastric Acid Disorder, MRX weight $=0.0$} \\
\hline Child in MMC & $\begin{array}{l}0.0035^{* * *} * \\
(0.0011)\end{array}$ & $\begin{array}{l}0.0064 * * * \\
(0.0012)\end{array}$ & $\begin{array}{l}0.0061 * * * \\
(0.0004)\end{array}$ & $14.50 \%$ \\
\hline Mean outcome & 0.042 & & & \\
\hline \multicolumn{5}{|c|}{ Panel I: The Effect of MMC on Nausea, MRX weight $=0.316$} \\
\hline Child in MMC & $\begin{array}{l}0.0173 \text { *** } \\
(0.0015)\end{array}$ & $\begin{array}{l}0.0072 * * * \\
(0.0008)\end{array}$ & $\begin{array}{l}0.0041 * * * \\
(0.0004)\end{array}$ & $9.80 \%$ \\
\hline Mean outcome & 0.042 & & & \\
\hline \multicolumn{5}{|c|}{ Panel J: The Effect of MMC on Cardiac, MRX weight $=1.175$} \\
\hline Child in MMC & $\begin{array}{l}0.0041 * * * \\
(0.0007)\end{array}$ & $\begin{array}{l}0.0026^{* * * *} \\
(0.0005)\end{array}$ & $\begin{array}{l}0.0020^{* * *} \\
(0.0002)\end{array}$ & $12.50 \%$ \\
\hline Mean outcome & 0.016 & & & \\
\hline
\end{tabular}




\begin{tabular}{|c|c|c|c|c|}
\hline & (1) & (2) & (3) & (4) \\
\hline \multicolumn{5}{|c|}{ Panel K: The Effect of MMC on Depression/Anxiety, MRx weight $=1.110$} \\
\hline Child in MMC & $\begin{array}{l}-0.0002 \\
(0.0006)\end{array}$ & $\begin{array}{l}0.0018 * * * \\
(0.0004)\end{array}$ & $\begin{array}{l}0.0018 * * * \\
(0.0002)\end{array}$ & $11.30 \%$ \\
\hline Mean outcome & 0.016 & & & \\
\hline
\end{tabular}

Notes: There are 2,960,843 observations. Controls include the child's gender, race, birth month, child and maternal age (single year of age dummies), birth weight ( $<1500 \mathrm{~g}, 1500-2499 \mathrm{~g}, 2500-2999 \mathrm{~g}, 3000-3499 \mathrm{~g} . .>=4500 \mathrm{~g})$, maternal education ( $<12,12$, some college, college plus, missing), Medicaid enrollment category, and monthly family income $(\$ 200, \$ 200-399, \ldots)$. Standard errors are clustered at the county level. In specification (3) controls include time-varying characteristics (income and age) and standard errors are clustered on patients. 
Table 4

Estimates of the Effect of MMC on Individual Risk Adjustment Scores.

\begin{tabular}{lllll}
\hline & $(\mathbf{1})$ & $(\mathbf{2})$ & $(\mathbf{3})$ & (4) \\
\hline County; Year Fixed Effects & NO & YES & YES & \%change from (3) \\
Controls (incl. birth certificate informtion) & NO & YES & YES & \\
Child Fixed Effects & NO & NO & YES & \\
Panel A: The Effect of MMC on Risk Adjustment Score & & & \\
Child in MMC & $0.139^{* * * *}$ & $0.035^{* * * *}$ & $0.020^{* * * *}$ & $17.40 \%$ \\
& $(0.006)$ & $(0.005)$ & $(0.001)$ & \\
Mean outcome & 0.115 & & & \\
Panel B: The Effect of MMC on Risk Adjustment Score Excluding Extra Weight for Asthma and ADHD \\
Child in MMC & $0.099^{* * * *}$ & $0.016^{* * * *}$ & $0.009^{* * * *}$ & $12.70 \%$ \\
& $(0.004)$ & $(0.003)$ & $(0.001)$ & \\
Mean outcome & 0.071 & & & \\
\hline
\end{tabular}

Notes: There are 2,960,843 observations. Controls include the child's gender, race, birth month, child and maternal age (single year of age dummies), birth weight (<1500 g, 1500-2499 g, 2500-2999 g, 3000-3499g .. >=4500 g), maternal education (<12, 12, some college, college plus, missing), Medicaid enrollment category, and monthly family income $(\$ 200, \$ 200-399, \ldots)$. Standard errors are clustered at the county level. In specification (3) controls include time-varying characteristics (income and age) and standard errors are clustered on patients. 
Table 5

The Effect of MMC on Outpatient Visits for Well and Sick Child Care, Past 12 Months.

\begin{tabular}{|c|c|c|c|c|}
\hline & (1) & (2) & (3) & (4) \\
\hline County; Year Fixed Effects & NO & YES & YES & $\%$ change from (3) \\
\hline Controls (incl. b.cert.) & NO & YES & YES & \\
\hline Child Fixed Effects & NO & NO & YES & \\
\hline \multicolumn{5}{|c|}{ Panel A: The Effect of MMC on Probability of Any Well-Child Visits } \\
\hline Child in MMC & $\begin{array}{l}0.121 * * * \\
(0.007)\end{array}$ & $\begin{array}{l}0.114 * * * \\
(0.007)\end{array}$ & $\begin{array}{l}0.071 * * * \\
(0.001)\end{array}$ & $16.20 \%$ \\
\hline Mean outcome & 0.439 & & & \\
\hline \multicolumn{5}{|c|}{ Panel B: The Effect of MMC on Probability of Any Blood Work } \\
\hline Child in MMC & $\begin{array}{l}0.036^{* * * *} \\
(0.010)\end{array}$ & $\begin{array}{l}0.026 * * * \\
(0.008)\end{array}$ & $\begin{array}{l}0.016 * * * \\
(0.001)\end{array}$ & $12.30 \%$ \\
\hline Mean outcome & 0.130 & & & \\
\hline \multicolumn{5}{|c|}{ Panel C: The Effect of MMC on Developmental Screen } \\
\hline Child in MMC & $\begin{array}{l}0.025 * * * \\
(0.004)\end{array}$ & $\begin{array}{l}0.010 * * * \\
(0.003)\end{array}$ & $\begin{array}{l}0.006 * * * \\
(0.000)\end{array}$ & $20.70 \%$ \\
\hline Mean outcome & 0.029 & & & \\
\hline \multicolumn{5}{|c|}{ Panel D: The Effect of MMC on Hearing Screen } \\
\hline Child in MMC & $\begin{array}{l}0.030 * * * \\
(0.005)\end{array}$ & $\begin{array}{l}0.027 * * * \\
(0.006)\end{array}$ & $\begin{array}{l}0.024 * * * \\
(0.000)\end{array}$ & $40.70 \%$ \\
\hline Mean outcome & 0.059 & & & \\
\hline \multicolumn{5}{|c|}{ Panel E: The Effect of MMC on the Probability of Receiving Any Vaccinations } \\
\hline Child in MCO & $\begin{array}{l}0.116^{* * * *} \\
(0.011)\end{array}$ & $\begin{array}{l}0.091 * * * \\
(0.009)\end{array}$ & $\begin{array}{l}0.065^{* * * *} \\
(0.001)\end{array}$ & $21.20 \%$ \\
\hline Mean outcome & 0.307 & & & \\
\hline \multicolumn{5}{|c|}{ Panel F: The Effect of MMC on Probability of Any Sick Visits } \\
\hline Child in MMC & $\begin{array}{l}0.089 * * * \\
(0.006)\end{array}$ & $\begin{array}{l}0.112 * * * \\
(0.006)\end{array}$ & $\begin{array}{l}0.077 * * * \\
(0.001)\end{array}$ & $9.60 \%$ \\
\hline Mean outcome & 0.802 & & & \\
\hline \multicolumn{5}{|c|}{ Panel G: The Effect of MMC on Probability of Sick Visits, MH Professional } \\
\hline Child in MMC & $\begin{array}{l}0.049 * * * \\
(0.010)\end{array}$ & $\begin{array}{l}0.039 \text { **** } \\
(0.004)\end{array}$ & $\begin{array}{l}0.022 * * * \\
(0.001)\end{array}$ & $9.00 \%$ \\
\hline Mean outcome & 0.244 & & & \\
\hline \multicolumn{5}{|c|}{ Panel H: The Effect of MMC on Probability of Sick Visits, Other Specialist } \\
\hline Child in MMC & $\begin{array}{l}-0.084 * * * \\
(0.012)\end{array}$ & $\begin{array}{l}-0.045^{* * *} \\
(0.012)\end{array}$ & $\begin{array}{l}-0.054 * * * \\
(0.001)\end{array}$ & $11.00 \%$ \\
\hline Mean outcome & 0.490 & & & \\
\hline
\end{tabular}

Notes: There are 2,960,843 observations. Controls include the child's gender, race, birth month, child and maternal age (single year of age dummies), birth weight (<1500 g, 1500-2499 g, 2500-2999 g, 3000-3499g .. >=4500 g), maternal education (<12, 12, some college, college plus, missing), Medicaid enrollment category, and monthly family income $(\$ 200, \$ 200-399, \ldots)$. Standard errors are clustered at the county level. In specification (3) controls include time-varying characteristics (income and age) and standard errors are clustered on patients. 


\section{Table 6}

Estimates of the Effect of MMC on Hospital Use in Past 12 Months.

\begin{tabular}{|c|c|c|c|c|}
\hline & (1) & (2) & (3) & (4) \\
\hline County; Year Fixed Effects & NO & YES & YES & $\%$ change from (3) \\
\hline Controls (incl. b.cert.) & NO & YES & YES & \\
\hline Child Fixed Effects & NO & NO & YES & \\
\hline \multicolumn{5}{|c|}{ Panel A: The Effect of MMC on Probability of Any Hospitalizations } \\
\hline Child in MMC & $\begin{array}{l}-0.0047 \text { *** } \\
(0.0007)\end{array}$ & $\begin{array}{l}0.0005 \\
(0.0004)\end{array}$ & $\begin{array}{l}-0.0002 \\
(0.0003)\end{array}$ & no change \\
\hline Mean outcome & 0.020 & & & \\
\hline \multicolumn{5}{|c|}{ Panel B: The Effect of MMC on Probability of Any Hospitalizations for Preventable Conditions } \\
\hline Child in MMC & $\begin{array}{l}-0.0016^{* * * *} \\
(0.0003)\end{array}$ & $\begin{array}{l}0.0003 * \\
(0.0002)\end{array}$ & $\begin{array}{l}-0.0000 \\
(0.0002)\end{array}$ & no change \\
\hline Mean outcome & 0.007 & & & \\
\hline \multicolumn{5}{|c|}{ Panel C: The Effect of MMC on Probability Of Any Hospitalization for non PC-Preventable Condition } \\
\hline Child in MMC & $\begin{array}{l}-0.0033^{* * * *} \\
(0.0004)\end{array}$ & $\begin{array}{l}0.0001 \\
(0.0003)\end{array}$ & $\begin{array}{l}-0.0001 \\
(0.0002)\end{array}$ & no change \\
\hline Mean outcome & 0.013 & & & \\
\hline
\end{tabular}

Notes: There are 2,960,843 observations. All birth-related claims were excluded. Controls include the child's gender, race, birth month, child and maternal age (single year of age dummies), birth weight $(<1500 \mathrm{~g}, 1500-2499 \mathrm{~g}, 2500-2999 \mathrm{~g}, 3000-3499 \mathrm{~g} \ldots>=4500 \mathrm{~g})$, maternal education $(<12,12$, some college, college plus, missing), Medicaid enrollment category, and monthly family income $(\$ 200, \$ 200-399, \ldots)$. Standard errors are clustered at the county level. In specification (3) controls include time-varying characteristics (income and age) and standard errors are clustered on patients. 
Table 7

Estimates of the Effect of MMC on ER Use in Past 12 Months.

\begin{tabular}{|c|c|c|c|c|}
\hline & (1) & (2) & (3) & (4) \\
\hline County; Year Fixed Effects & NO & YES & YES & $\%$ change from (3) \\
\hline Controls (incl. b.cert.) & NO & YES & YES & \\
\hline Child Fixed Effects & NO & NO & YES & \\
\hline \multicolumn{5}{|c|}{ Panel A: The Effect of MMC on Probability Of Any ER visits } \\
\hline Child in MMC & $\begin{array}{l}0.02165 * * * \\
(0.00441)\end{array}$ & $\begin{array}{l}0.03706^{* * * *} \\
(0.00297)\end{array}$ & $\begin{array}{l}0.0195 * * * \\
(0.0008)\end{array}$ & $7.68 \%$ \\
\hline Mean outcome & 0.254 & & & \\
\hline \multicolumn{5}{|c|}{ Panel B: The Effect of MMC on Probability of Any ER Visit for PC-Preventable Conditions } \\
\hline Child in MMC & $\begin{array}{l}0.0027 * * * \\
(0.0006)\end{array}$ & $\begin{array}{l}0.0042 * * * \\
(0.0004)\end{array}$ & $\begin{array}{l}0.0021 * * * \\
(0.0002)\end{array}$ & $7.20 \%$ \\
\hline Mean outcome & 0.029 & & & \\
\hline \multicolumn{5}{|c|}{ Panel B: The Effect of MMC on Any ER Visit for Asthma as Primary Diagnosis } \\
\hline Child in MMC & $\begin{array}{l}0.0020 * * * \\
(0.0003)\end{array}$ & $\begin{array}{l}0.0013 * * * \\
(0.0002)\end{array}$ & $\begin{array}{l}0.0009 * * * \\
(0.0002)\end{array}$ & $11.30 \%$ \\
\hline Mean outcome & 0.008 & & & \\
\hline \multicolumn{5}{|c|}{ Panel C: The Effect of MMC on Probability of Any ER Visit for PC-Treatable Conditions } \\
\hline Child in MMC & $\begin{array}{l}0.0056 * * * \\
(0.0018)\end{array}$ & $\begin{array}{l}0.0138 * * * \\
(0.0012)\end{array}$ & $\begin{array}{l}0.0075^{* * *} * \\
(0.0004)\end{array}$ & $8.10 \%$ \\
\hline Mean outcome & & 0.093 & & \\
\hline \multicolumn{5}{|c|}{ Panel D: The Effect of MMC on Probability of Any ER Visit for Not PC Preventable/Treatable } \\
\hline Child in MMC & $\begin{array}{l}0.0034 * * * \\
(0.0006)\end{array}$ & $\begin{array}{l}0.0043 * * * \\
(0.0005)\end{array}$ & $\begin{array}{l}0.0027 * * * \\
(0.0002)\end{array}$ & $11.30 \%$ \\
\hline Mean outcome & 0.024 & & & \\
\hline \multicolumn{5}{|c|}{ Panel E: The Effect of MMC on Probability of Any ER Visit for Non-urgent Conditions } \\
\hline Child in MMC & $\begin{array}{l}0.0084 * * * \\
(0.0017)\end{array}$ & $\begin{array}{l}0.0121 * * * \\
(0.0011)\end{array}$ & $\begin{array}{l}0.0067 * * * \\
(0.0004)\end{array}$ & $8.50 \%$ \\
\hline Mean outcome & 0.079 & & & \\
\hline \multicolumn{5}{|c|}{ Panel F: The Effect of MMC on the Probability of an ER Visit for Injury } \\
\hline Child in MMC & $\begin{array}{l}0.0084 * * * \\
(0.0019)\end{array}$ & $\begin{array}{l}0.0133 * * * \\
(0.0011)\end{array}$ & $\begin{array}{l}0.0062^{* * * *} \\
(0.0005)\end{array}$ & $7.30 \%$ \\
\hline Mean outcome & 0.085 & & & \\
\hline
\end{tabular}

Notes: There are 2,960,843 observations. Controls include the child's gender, race, birth month, child and maternal age (single year of age dummies), birth weight ( $<1500 \mathrm{~g}, 1500-2499 \mathrm{~g}, 2500-2999 \mathrm{~g}, 3000-3499 \mathrm{~g} \ldots>=4500 \mathrm{~g})$, maternal education $(<12,12$, some college, college plus, missing), Medicaid enrollment category, and monthly family income $(\$ 200, \$ 200-399, \ldots)$. Standard errors are clustered at the county level. In specification (3) controls include time-varying characteristics (income and age) and standard errors are clustered on patients etc.

To classify ER visits we follow Billings et al. (2000). They use diagnosis to define: non-urgent ER visits (e.g. sore throat); PC-treatable (e.g. ear infection); PC-preventable (e.g. asthma attack); Non-preventable visits (e.g. a cardiac dysrhythmia); Injuries (which are treated as a separate category), and other. Because there can be more than one diagnosis on a record, the subclasses of ER visits can add to more than the total number of visits. 


\section{Table 8}

Estimates of the Effect of MMC on Adherence to Asthma Medication Regime. Conditional on Having an Asthma Event at Some Time While in Sample.

\begin{tabular}{|c|c|c|c|c|}
\hline & (1) & (2) & (3) & (4) \\
\hline County; Year Fixed Effects & NO & YES & YES & $\%$ change from (3) \\
\hline Controls (incl. b.cert.) & NO & YES & YES & \\
\hline Child Fixed Effects & NO & NO & YES & \\
\hline \multicolumn{5}{|c|}{ Panel A: The Effect of MMC on Probability of Filling Prescriptions Covering 3+ Months } \\
\hline Child in MMC & $\begin{array}{l}0.0242 * * * \\
(0.0030)\end{array}$ & $\begin{array}{l}0.0004 \\
(0.0028)\end{array}$ & $\begin{array}{l}0.0055^{* * * *} \\
(0.0008)\end{array}$ & $5.0 \%$ \\
\hline Mean outcome & 0.109 & & & \\
\hline \multicolumn{5}{|c|}{ Panel B: The Effect of MMC on Probability of Filling Prescriptions Covering $6+$ Months } \\
\hline Child in MMC & $\begin{array}{l}0.0114 * * * \\
(0.0018)\end{array}$ & $\begin{array}{l}-0.0002 \\
(0.0018)\end{array}$ & $\begin{array}{l}0.0014^{* *} \\
(0.0006)\end{array}$ & $2.7 \%$ \\
\hline Mean outcome & 0.051 & & & \\
\hline \multicolumn{5}{|c|}{ Panel C: Effect of MMC on Prob. of Only Filling Prescriptions for Long Acting Steroids, Past 12 months } \\
\hline Child in MMC & $\begin{array}{l}0.0153^{* * * *} \\
(0.0017)\end{array}$ & $\begin{array}{l}0.0048 * * \\
(0.0018)\end{array}$ & $\begin{array}{l}0.0042 * * * \\
(0.0005)\end{array}$ & $9.8 \%$ \\
\hline Mean outcome & 0.043 & & & \\
\hline \multicolumn{5}{|c|}{ Panel D: Effect of MMC on Prob. of Only Filling Prescriptions for Asthma Attack Relievers, Past 12 month. } \\
\hline Child in MMC & $\begin{array}{l}0.0171^{* * * *} \\
(0.0010)\end{array}$ & $\begin{array}{l}0.0031 * * * \\
(0.0008)\end{array}$ & $\begin{array}{l}0.0023 * * * \\
(0.0004)\end{array}$ & $8.5 \%$ \\
\hline Mean outcome & 0.027 & & & \\
\hline
\end{tabular}

Notes: There are 1,346,922 observations. Controls include the child's gender, race, birth month, child and maternal age (single year of age dummies), birth weight ( $<1500 \mathrm{~g}, 1500-2499 \mathrm{~g}, 2500-2999 \mathrm{~g}, 3000-3499 \mathrm{~g} \ldots>=4500 \mathrm{~g})$, maternal education $(<12$, 12, some college, college plus, missing), Medicaid enrollment category, and monthly family income (\$200, \$200-399,...). Standard errors are clustered at the county level. In specification (3) controls include time-varying characteristics (income and age) and standard errors are clustered on patients. 